\title{
A Systematic Review of Multiple Linear Regression-Based Limited Sampling Strategies for Mycophenolic Acid Area Under the Concentration-Time Curve Estimation
}

\author{
Joanna Sobiak ${ }^{1}$ (D) Matylda Resztak ${ }^{1}$ \\ Accepted: 17 August 2021 / Published online: 4 September 2021 \\ (c) The Author(s) 2021
}

\begin{abstract}
Background and Objective One approach of therapeutic drug monitoring in the case of mycophenolic acid (MPA) is a limited sampling strategy (LSS), which allows the evaluation of the area under the concentration-time curve (AUC) based on few concentrations. The aim of this systematic review was to review the MPA LSSs and define the most frequent time points for MPA determination in patients with different indications for mycophenolate mofetil (MMF) administration.

Methods The literature was comprehensively searched in July 2021 using PubMed, Scopus, and Medline databases. Original articles determining multiple linear regression (MLR)-based LSSs for MPA and its free form (fMPA) were included. Studies on enteric-coated mycophenolic sodium, previously established LSS, Bayesian estimator, and different than twice a day dosing were excluded. Data were analyzed separately for (1) adult renal transplant recipients, (2) adults with other than renal transplantation indication, and (3) for pediatric patients.

Results A total of 27, 17, and 11 studies were found for groups 1,2, and 3, respectively, and 126 MLR-based LSS formulae ( $n=120$ for MPA, $n=6$ for fMPA) were included in the review. Three time-point equations were the most frequent. Four MPA LSSs: $2.8401+5.7435 \times \mathrm{C} 0+0.2655 \times \mathrm{C} 0.5+1.1546 \times \mathrm{C} 1+2.8971 \times \mathrm{C} 4$ for adult renal transplant recipients, 1.78 $3+1.248 \times \mathrm{C} 1+0.888 \times \mathrm{C} 2+8.027 \times \mathrm{C} 4$ for adults after islet transplantation, $0.10+11.15 \times \mathrm{C} 0+0.42 \times \mathrm{C} 1+2.80 \times \mathrm{C} 2$ for adults after heart transplantation, and $8.217+3.163 \times \mathrm{C} 0+0.994 \times \mathrm{C} 1+1.334 \times \mathrm{C} 2+4.183 \times \mathrm{C} 4$ for pediatric renal transplant recipients, plus one fMPA LSS, $34.2+1.12 \times \mathrm{C} 1+1.29 \times \mathrm{C} 2+2.28 \times \mathrm{C} 4+3.95 \times \mathrm{C} 6$ for adult liver transplant recipients, seemed to be the most promising and should be validated in independent patient groups before introduction into clinical practice. The LSSs for pediatric patients were few and not fully characterized. There were only a few fMPA LSSs although fMPA is a pharmacologically active form of the drug.

Conclusions The review includes updated MPA LSSs, e.g., for different MPA formulations (suspension, dispersible tablets), generic form, and intravenous administration for adult and pediatric patients, and emphasizes the need of individual therapeutic approaches according to MMF indication. Five MLR-based MPA LSSs might be implemented into clinical practice after evaluation in independent groups of patients. Further studies are required, e.g., to establish fMPA LSS in pediatric patients.
\end{abstract}

Joanna Sobiak

jsobiak@ump.edu.pl

1 Department of Physical Pharmacy and Pharmacokinetics,

Poznan University of Medical Sciences, 6 Święcickiego

Street, 60-781 Poznan, Poland 


\section{Key Points}

This review summarizes mycophenolic acid (MPA) and its free form (fMPA) limited sampling strategies (LSSs), calculated with multiple linear regression for adult and pediatric patients with different mycophenolate mofetil (MMF) indications, and includes detailed information on each LSS (type of calcineurin inhibitor co-administered, duration of MMF treatment, predictive performance of LSS).

The review includes LSSs not only for renal transplant recipients, which is the most frequent MMF indication, but also for patients after lung, heart, islet, liver, or hematopoietic stem cell transplantation, as well as patients with autoimmune diseases and children with nephrotic syndrome for whom therapeutic drug monitoring is of importance.

Four MPA LSSs (for adult patients after renal, islet, and heart transplantation and pediatric renal transplant recipients) and one fMPA LSS (for adult liver transplant recipients) were the most promising and should be validated in independent groups before introduction into clinical practice.

\section{Introduction}

Mycophenolate mofetil (MMF) is an immunosuppressive drug, whose active form is mycophenolic acid (MPA). MMF is administered after solid organ transplantation [1] as the prophylaxis against acute rejection, as well as being given in autoimmune diseases [2] and nephrotic syndrome [3, 4], as well as in atopic dermatitis [5]. MPA is highly protein bound (97-99\%) with free MPA (fMPA) being pharmacologically active [6]. MPA pharmacokinetics are complex and highly variable, with numerous factors influencing the interindividual variability [2].

Due to the pharmacokinetic variability, therapeutic drug monitoring (TDM) in the case of MPA is recommended in clinical practice $[2,7]$. TDM has been shown to be favorable not only in renal transplant recipients [8] but also in patients with lupus nephritis [9] and steroid-dependent nephrotic syndrome [10-12]. The most accurate approach to TDM is the determination of the full pharmacokinetic profile of the drug and calculation of the area under the concentration-time curve from 0 to $12 \mathrm{~h}\left(\mathrm{AUC}_{0-12}\right)$, as the concentration determined before the next dose $\left(C_{\text {trough }}\right)$ does not reflect the overall exposure to MPA [8]. Determining $\mathrm{AUC}_{0-12}$ is, however, time-consuming, expensive, and uncomfortable for patients; therefore, different approaches of TDM are being investigated.

One of the possibilities of TDM is establishing a limited sampling strategy (LSS) and predicting $\mathrm{AUC}_{0-12}$ on the basis of only a few blood samples [8]. LSS may be calculated using a Bayesian approach or multiple linear regression (MLR) analysis, which uses an equation derived from stepwise regression analysis based on concentrations measured at pre-defined times after dosing [7, 13]. Each MLR LSS constitutes an equation: AUC $=b+M_{t 1} \times C_{t 1}+M_{t 2} \times$ $C_{t 2}+M_{t 3} \times C_{t 3}+\ldots+M_{t i} \times C_{t i}$, where AUC indicates predicted AUC, $b$ indicates the intercept, $C_{t 1}, C_{t 2}, C_{t 3}, C_{t i}$ indicate the concentrations obtained at $t_{1} t_{2}, t_{3}$ and $t_{\mathrm{I}}$ time points, respectively, and $M_{t 1}, M_{t 2}, M_{t 3}$ and $M_{t i}$ indicate the coefficients associated with each timed concentration [14]. Such strategies have been proposed for MPA in many groups of patients [15-19], with emphasis that each LSS should be applied to the same group of patients for whom it was established [20]. As it does not depend on the pharmacokinetic model of the drug and can be calculated with simple software or manually [14], MLR is easier to use in clinical practice than Bayesian analysis; however, the MLR approach has some limitations. First is the reliance of the equations' accuracy on exact times of blood sample collection [7, 14]. Second is the poor prediction of the exposure to the drug in patients with abnormal pharmacokinetics [14]. And third is its applicability limitation for the dosage regimen and the population from which MLR LSS was derived. The main disadvantage of the Bayesian approach is the requirement of advanced software and highly-qualified staff. However, as this methodology uses the population approach [14], it does not require strict adherence to sampling times and is characterized by better precision and accuracy [7, 14]. The aim of this systematic review was to summarize the MPA LSSs established with MLR for different groups of patients. The summary also aimed at defining the most frequently used sampling points for MPA determination.

\section{Methods}

\subsection{Search Strategy}

The literature databases PubMed, Scopus, and Medline were comprehensively searched in July 2021 with the combination of 'mycophenolic acid' or 'mycophenolate mofetil' and the terms, 'limited sampling strategy', 'limited sampling strategies', 'limited sampling', 'optimal sampling', 'sparse sampling', and 'minimal sampling'. Additionally, the reference lists of studies found in the literature were searched to detect articles potentially eligible for inclusion. Only studies published in English were included. 


\subsection{Study Selection}

The flow diagram of article selection is presented in Fig. 1.

\subsection{Inclusion Criteria}

Original articles determining LSS based on MLR calculations for MPA and fMPA were included. The studies concerned adult and pediatric patients receiving MMF as a prophylaxis after transplantation (solid organ, hematopoietic stem cells) to treat autoimmune diseases or nephrotic syndrome.

\subsection{Exclusion Criteria}

The articles describing LSS for enteric-coated mycophenolic sodium (EC-MPS) were excluded, as there is an evident difference in MPA pharmacokinetics for these two formulations, MMF and EC-MPS [unpredictable absorption profile, delayed maximum concentration $\left(C_{\max }\right)$, and higher pre-dose concentration $(\mathrm{C} 0)$ after EC-MPS administration] [2, 21].
Therefore, in our opinion, EC-MPS LSSs should be analyzed separately. Also, the studies using previously established LSS, those with Bayesian estimator, with different than twice a day MMF dosing schedules and reviews were excluded. There are some studies establishing MPA LSSs with a Bayesian estimator, and although this approach has some advantages (e.g., better accuracy and precision, the lack of strict adherence to sampling times, and number of samples [7]), we decided to include only MLR-based MPA LSSs due to the excessive amount of data and the difficulty in analyzing MLR-based LSSs and Bayesian-approach LSSs.

\subsection{Data Analysis}

The data were analyzed according to the most frequently used time points in three groups of patients treated with MMF: (1) adult renal transplant recipients, (2) adults receiving MMF due to other indication than renal transplantation, and (3) pediatric patients. The most frequently used time points were calculated in relation to the number of LSSs equations in each group, and as the percentage of the sum

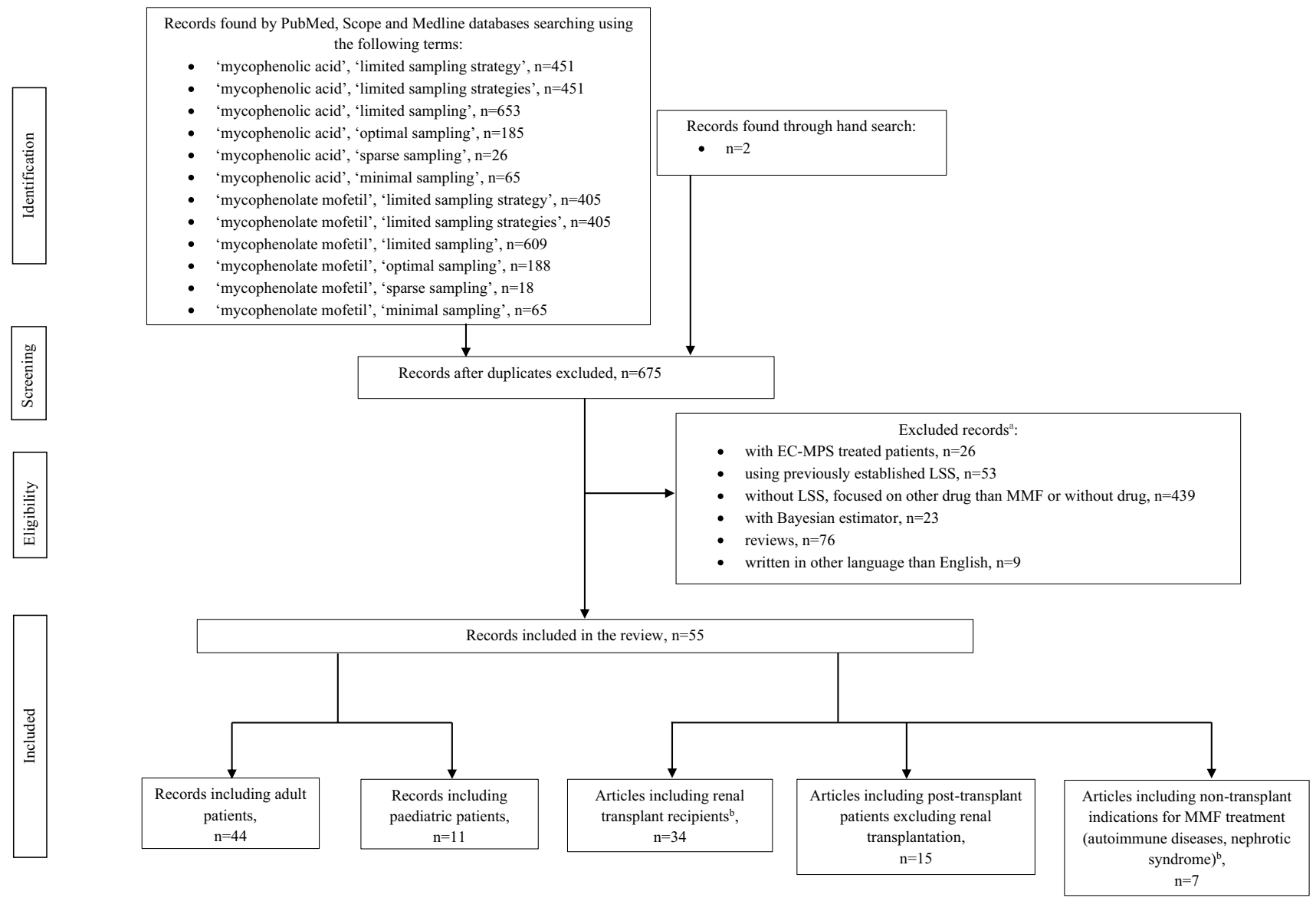

Fig. 1. The flow diagram of article selection. ${ }^{\mathrm{a}} \mathrm{Six}$ records fulfilled more than one exclusion condition. ${ }^{\mathrm{b}}$ One study included pediatric patients after renal transplantation as well as with autoimmune diseases 
of all time points used in all LSSs equations in each group of patients. Whenever possible, the predictive performance results of the LSSs (bias, precision, validation group) were included in the review, as was the information whether the validation was internal or external. If the LSS was validated with data which were at the same time used for LSS determination, then the validation was internal. If the data from a separate group of patients (or the patients were divided into two groups) were used for the validation, then the validation was external. The best MPA LSSs were chosen based on the following criteria of the predictive performance: $r^{2}>0.950$, bias and precision $<10 \%$.

\section{Results}

\subsection{Study Identification and Characteristics}

The search of the literature returned 55 studies concerning MLR LSSs for MPA and fMPA. In this review, 126 MLRbased LSS formulae were included [16-20, 22-71], among which two studies included both MPA and fMPA LSS [40, 61] and one study concerned only fMPA LSS [51]. There was one study which considered patients receiving either MMF or EC-MPS as one group and established the MPA LSSs for them [30]. If the study included several LSSs, those which the authors described as the best or those with the best $r^{2}$ were chosen. Most of the studies concerned adult patients, who were treated with MMF after renal transplantation ( $n=27$; Table 1$)$ or due to other indications $(n=17$; Table 2). A total of 11 studies with MLR-based LSSs were found for children (Table 3). The data are presented in the tables in chronological order (the newest first).

Based on all LSSs found in the literature, blood samples for MPA determination were collected before the administration of the next dose and subsequently at $20 \mathrm{~min}, 0.5 \mathrm{~h}, 40$ min, 1 h, 1.25 h, 1.5 h, 2 h, 3 h, 3.5 h, 4 h, 6 h, 7 h, 8 h, 9 h, $10 \mathrm{~h}$, and $12 \mathrm{~h}$ afterwards. These time points were included in LSSs as C20min, C0.5, C40min, C1, C1.25, C1.5, C2, $\mathrm{C} 3, \mathrm{C} 3.5, \mathrm{C} 4, \mathrm{C} 6, \mathrm{C} 7, \mathrm{C} 8, \mathrm{C} 9, \mathrm{C} 10$ and $\mathrm{C} 12$, where ' $\mathrm{C}$ ' is the concentration. In the LSS equations, MPA concentration determined before the next MMF dose is named as $\mathrm{C} 0$; however, it must be emphasized that, due to administration of MMF every $12 \mathrm{~h}$, this concentration is the pre-dose trough concentration and should be named as $C_{\text {trough }}$ or $C_{\text {min. }}$. In the MLR-based LSSs, it is more convenient to write $\mathrm{C} 0$ instead of $C_{\text {trough }}$.

For most of the studies, the predictive performance results were found. Bias was expressed as mean or median percentage prediction error; however, in some studies, bias was expressed as mean prediction error (MPE) or mean bias with units of the concentration multiplied by time. Precision was expressed as mean or median absolute percentage prediction error, however, in some studies, precision was expressed as mean absolute error with units of the concentration multiplied by time. Root square mean prediction error (RMSE) was also calculated in some studies as precision. Validation methods, if performed, included the bootstrap method, jackknife method, validation group, or cross-validation. Some LSSs were characterized by the good guess which is the percentage of the predicted AUC $\left(\mathrm{AUC}_{\text {pred }}\right)$ within $\pm 15 \%$, $\pm 20 \%$, or $\pm 25 \%$ of the calculated AUC $\left(\mathrm{AUC}_{\text {total }}\right)$.

\subsection{The MLR-Based LSSs for Adult Renal Transplant Recipients}

As MMF was primarily administered in prophylaxis of acute rejection in solid organ transplantation, most of the studies concerning MLR LSSs included renal transplant recipients [22-48] (Table 1). Three fMPA LSSs were included in the results as the occurrence of $C_{\max }$ and $C_{\max 2}$ should be the same for MPA and fMPA.

The equations included up to five time points with three time-point LSSs being the most frequent (59\%). Of all the time points, those collected within 0-2 $\mathrm{h}$ after MMF administration constituted $58 \%$ of the total, whereas sampling between 3-5 $\mathrm{h}$ and 6-12 $\mathrm{h}$ after drug administration constituted $26 \%$ and $16 \%$, respectively.

Of 59 MLR equations, the most frequently used time points were $\mathrm{C} 4$ and $\mathrm{C} 2$, which were included in $32(54 \%)$ and $29(49 \%)$ equations, respectively, and constituted $18 \%$ and $16 \%$ of the sum of all time points from 59 equations, respectively. The 22 (37\%) equations including $\mathrm{C} 0$ and $\mathrm{C} 0$ constituted $13 \%$ of all time points. The most frequently included time point within 6-12 $\mathrm{h}$ after MMF administration was C6 (19\% of equations). Two LSSs included C12 which is equal to $\mathrm{C} 0$ if blood samples are collected in steady-state; however, $\mathrm{C} 12$ was not analyzed with $\mathrm{C} 0$ when calculating the percentage.

If analyzed according to the calcineurin inhibitor coadministered, among all equations established for MMF and cyclosporine (CsA) treatment $(n=28)$, the most frequent time points in LSSs were C2 (18\% of all time points, $54 \%$ of the equations), and $\mathrm{C} 4$ (17\% of all time points, $50 \%$ of the equations). For tacrolimus (Tac) co-administration (30 LSSs), the time points most often included were C4 (19\% of all time points, $57 \%$ of the equations), and $\mathrm{C} 2$ (15\% of all time points, $47 \%$ of the equations). LSS established by Gaies et al. [25] was not included as the authors did not separately analyze patients receiving CsA and Tac.

With respect to the post-transplant period, the LSSs were divided into two groups: established for patients less than 1 month after transplantation, and longer than 3 months after transplantation. The LSSs established in the early post-transplant period $(n=22)$ most frequently included $\mathrm{C} 2$ (25\% of all time points, $73 \%$ of 


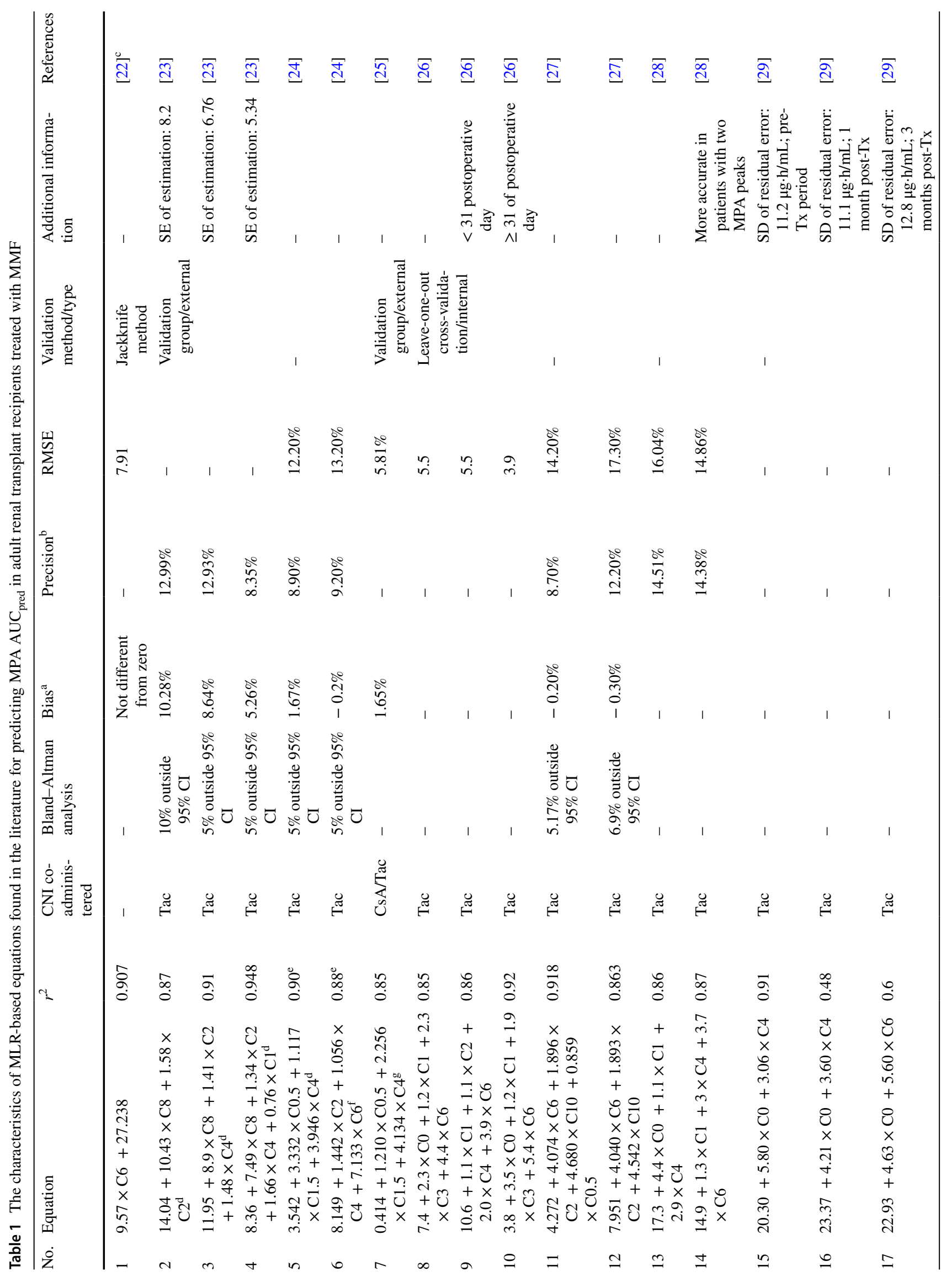




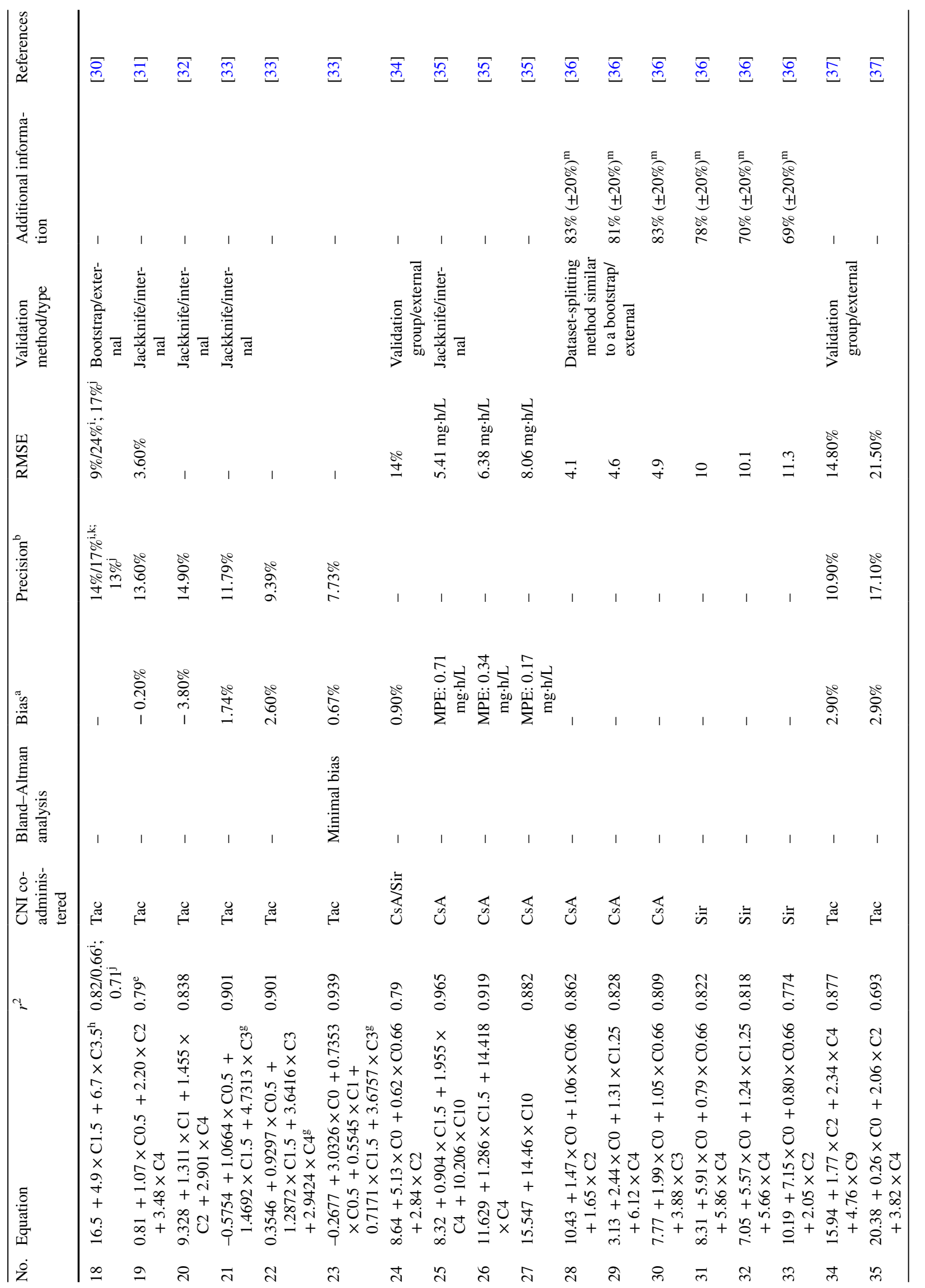




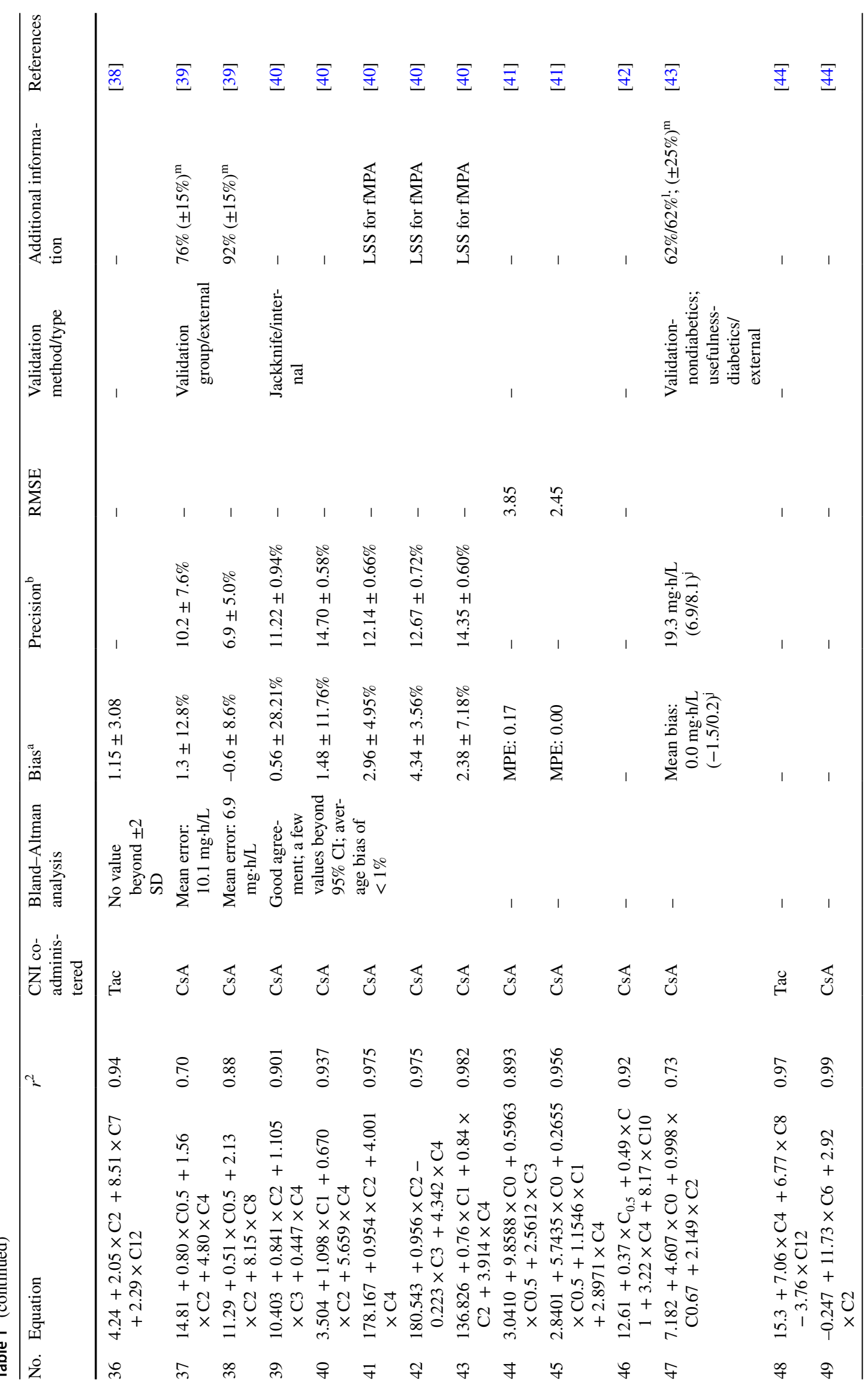




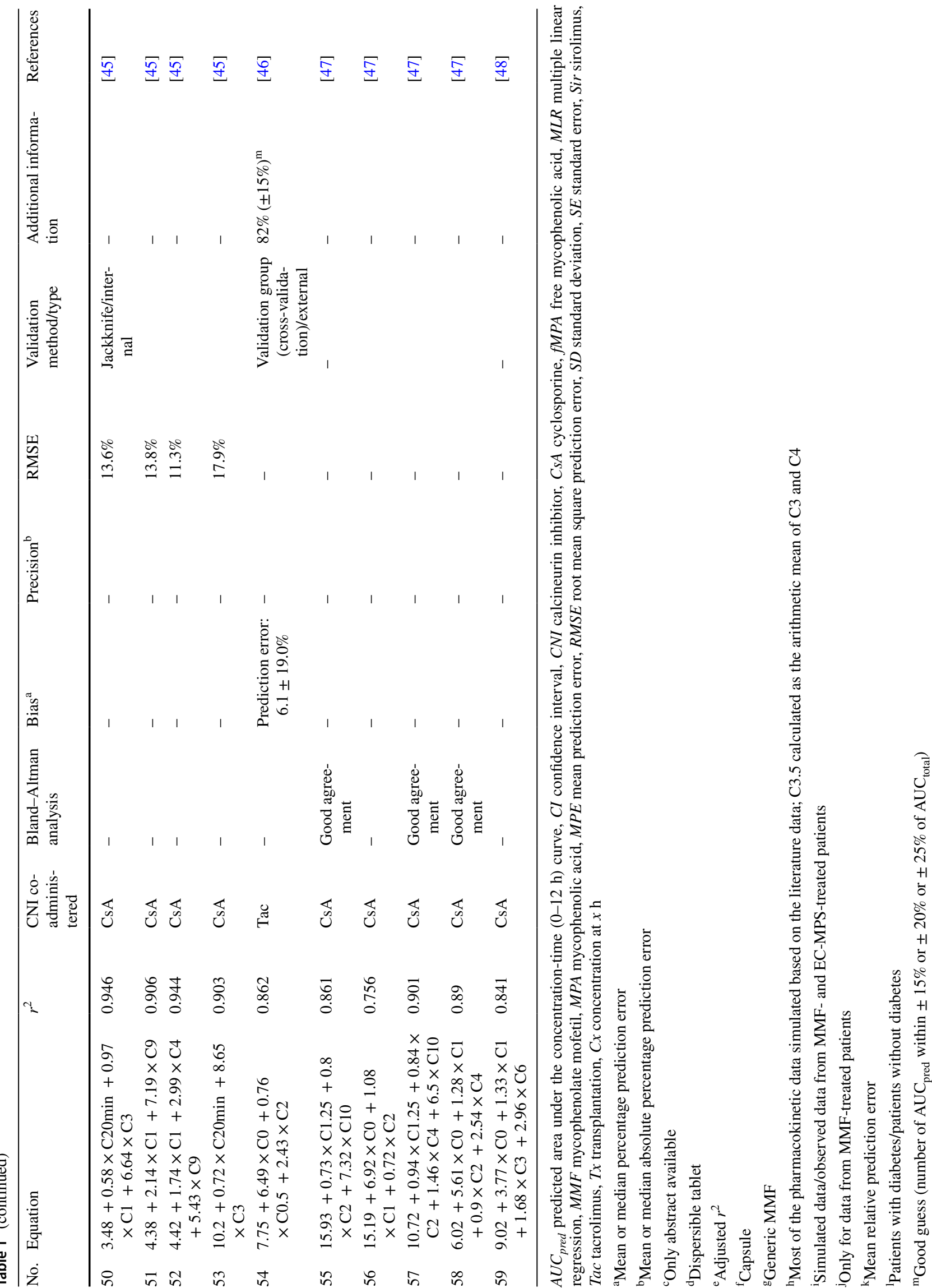




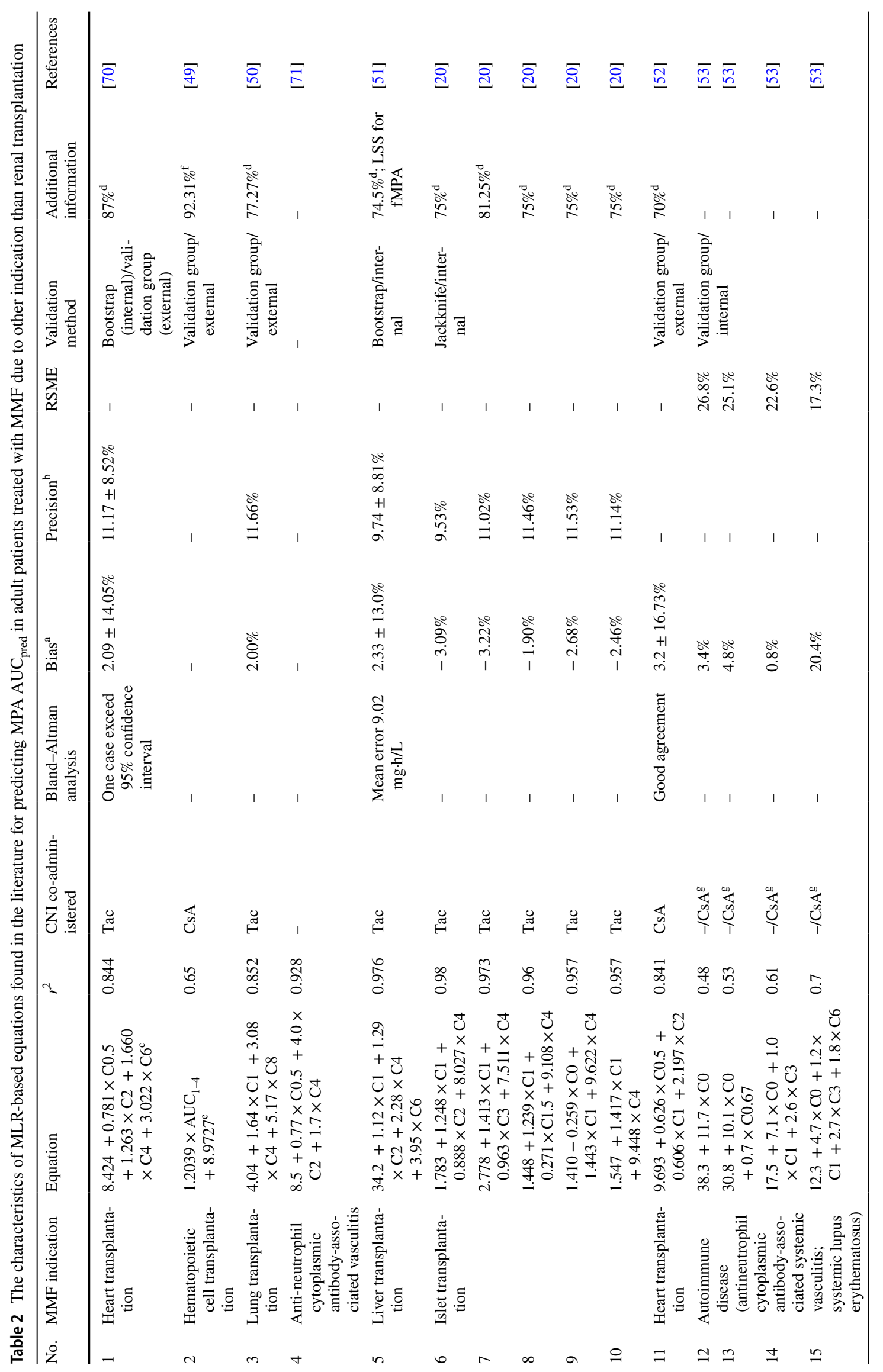




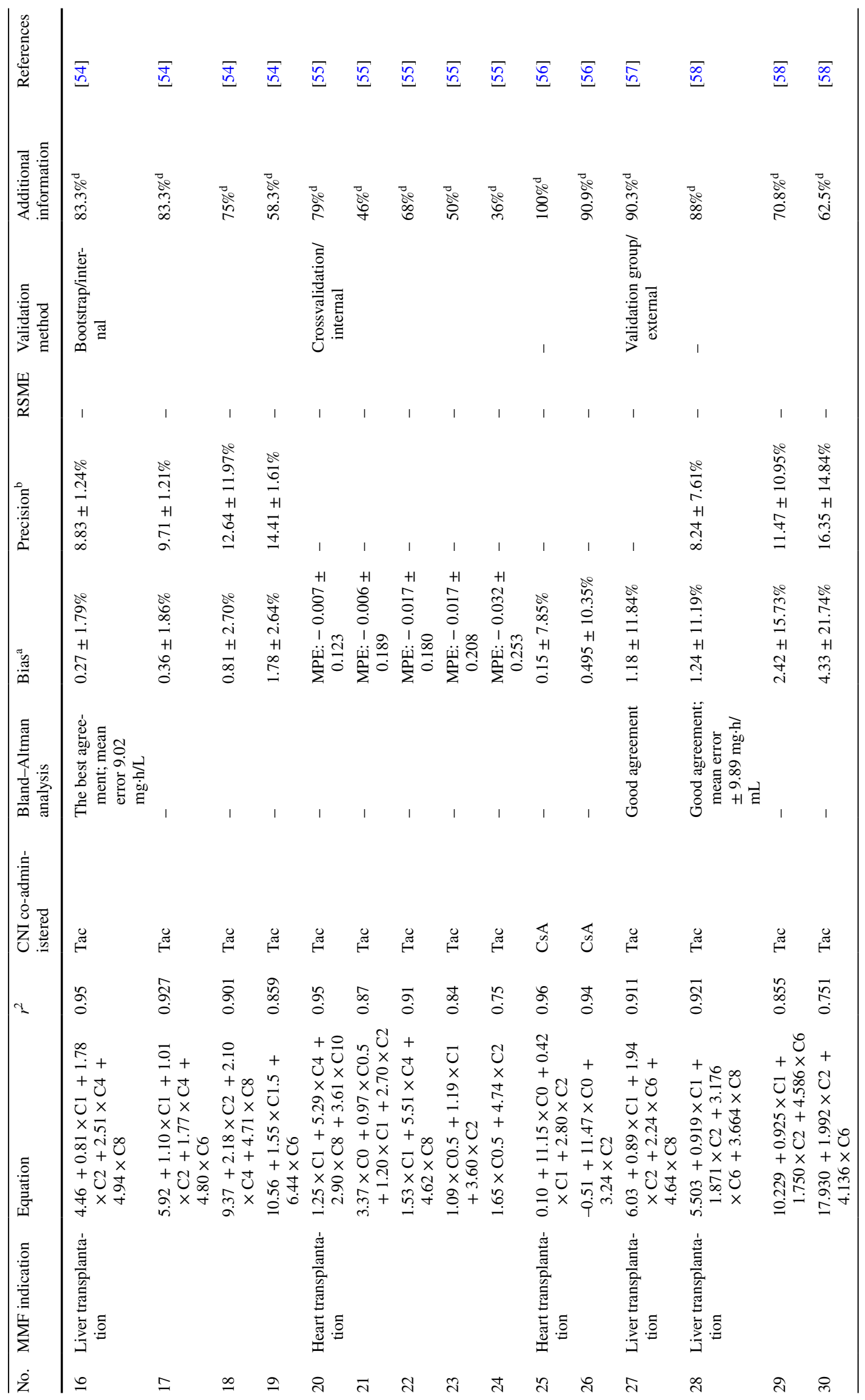




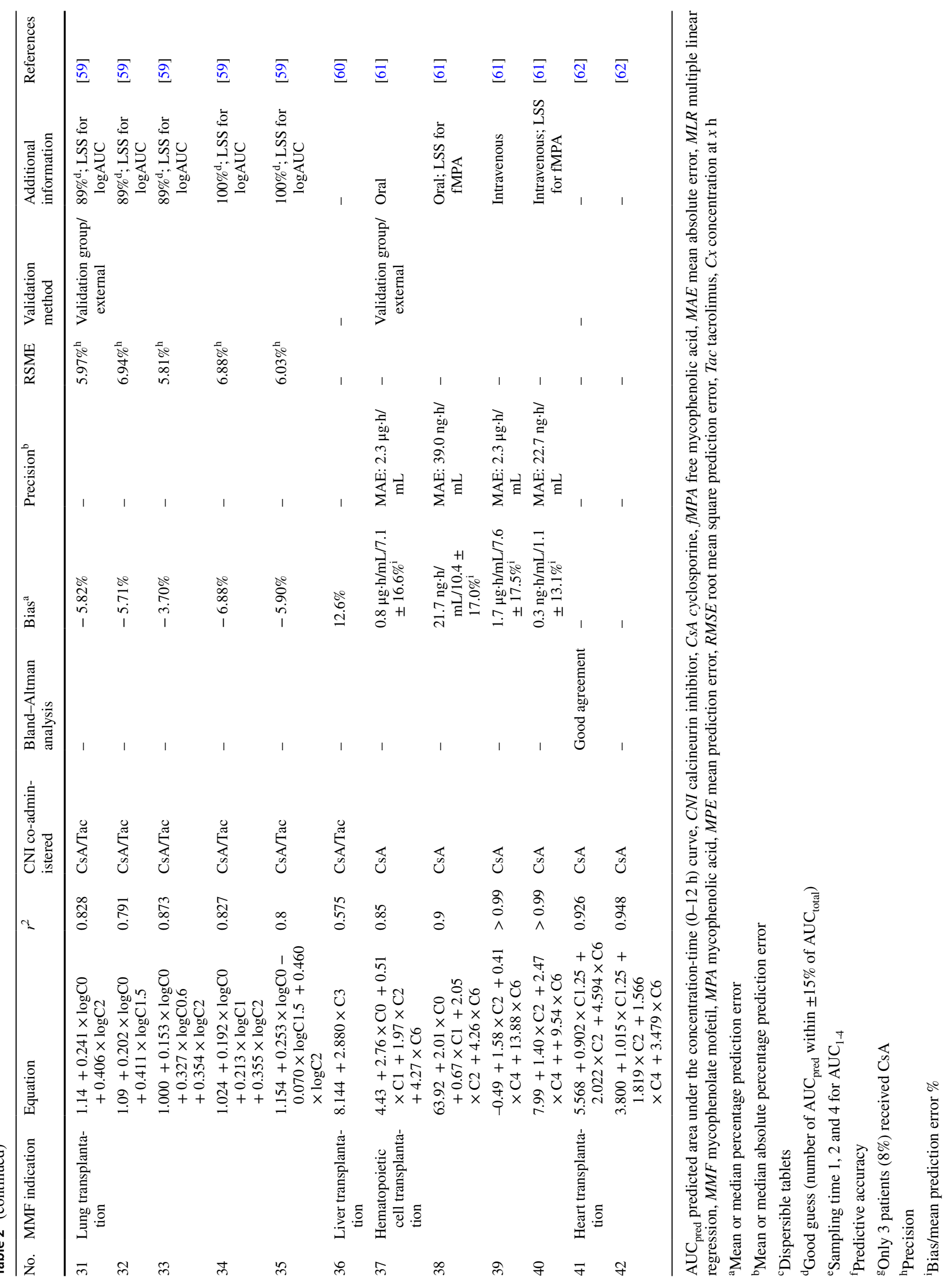




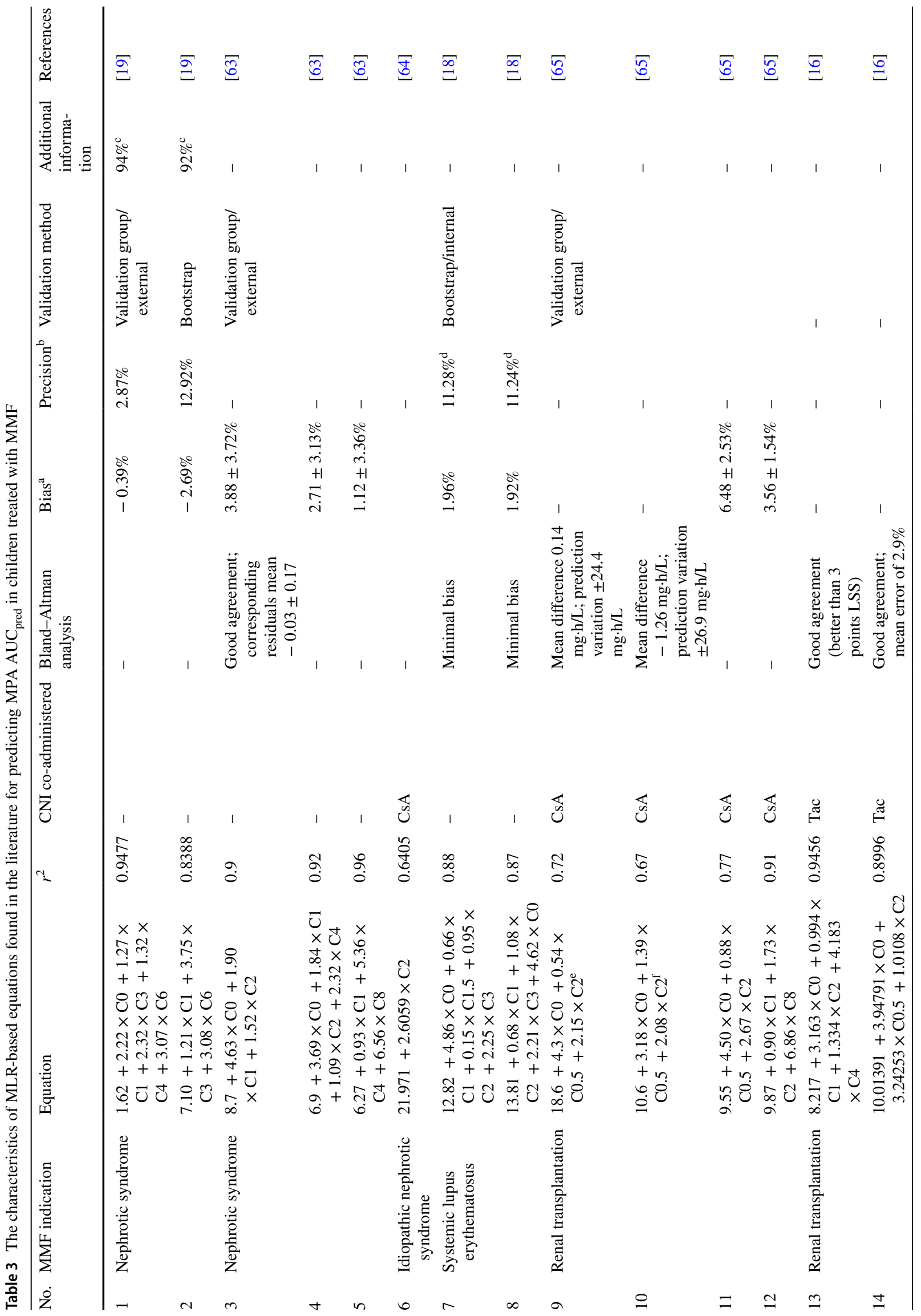




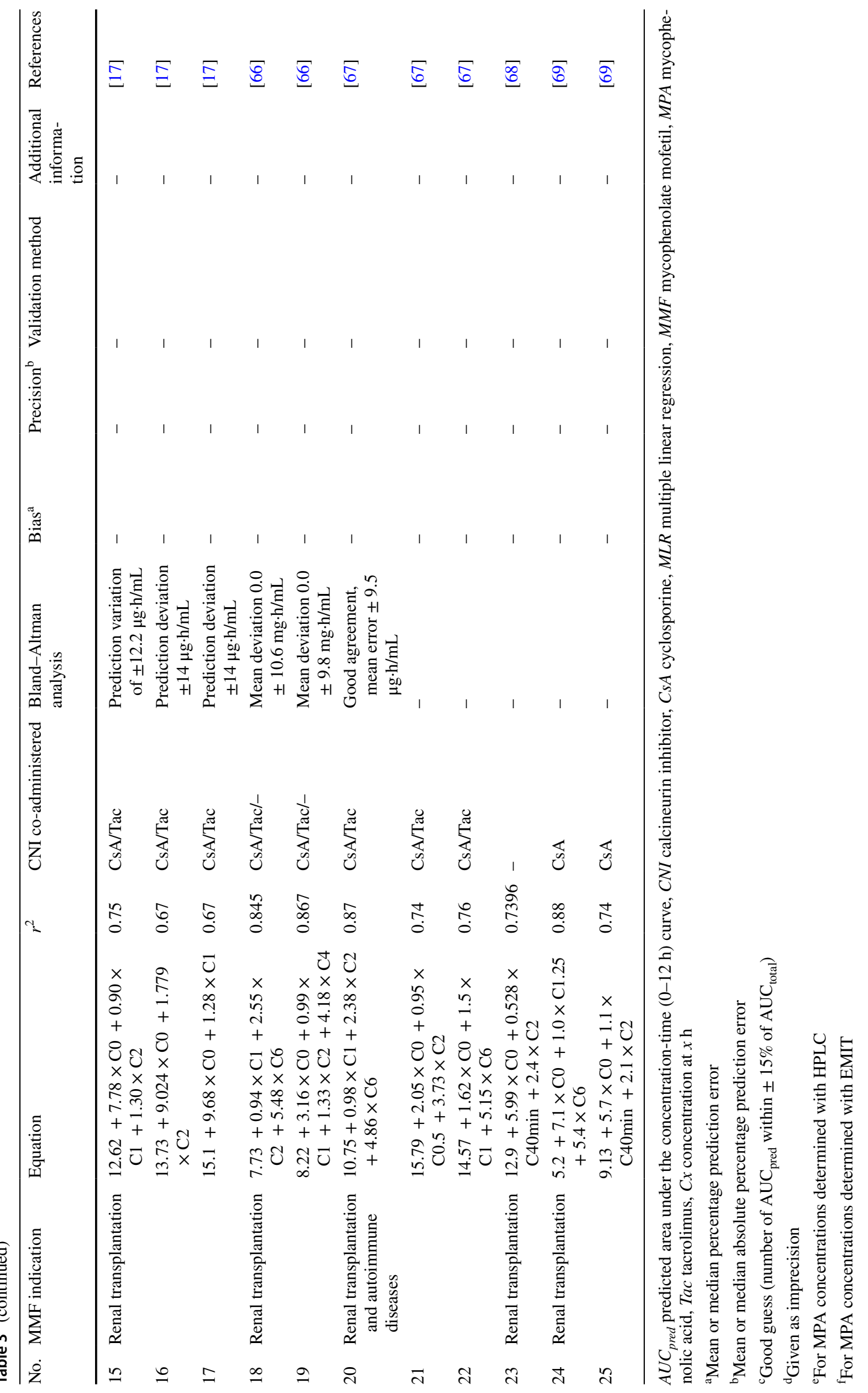


the equations), and $\mathrm{C} 4$ (22\% of all time points, $64 \%$ of the equations). For LSSs established in the stable posttransplant period $(n=16)$, the concentrations most often used included $\mathrm{C} 1$ (20\% of all time points, $63 \%$ of the equations) and C3 (14\% of all time points, $44 \%$ of the equations). In several studies, MPA concentrations and MPA LSSs were determined in patients in the early post-transplant period together with those in the stable post-transplant period. Therefore, those LSSs were not included in this analysis.

The worse $r^{2}$ was for LSS established 1 month after transplantation and included two time points ( $\mathrm{C} 0$ and $\mathrm{C} 4$; $\left.r^{2}<0.5\right)$ [29]. Interestingly, the LSS with the same time points ( $\mathrm{C} 0$ and $\mathrm{C} 4)$, established in the same study but before transplantation, was characterized by much better $r^{2}$ (0.91) [29]. The value of $r^{2}$ above 0.98 was obtained for three LSSs, among which one included five time points [33], one included two time points [44], and one concerned fMPA [40]. The bias was within the range of -3.80 to $10.28 \%$. MPA LSS in one study was characterized by mean bias equal $0 \mathrm{mg} \mathrm{h} / \mathrm{L}$ [41]. In other study, bias of one LSS was expressed as MPE and equal to 0.00 [43]. The precision defined as mean or median absolute percentage prediction error or RMSE ranged from 6.9 to $17.10 \%$ and 3.60 to $24 \%$, respectively. Some studies calculated the good guess. The best results amounted to $92 \%$ [39], 83\% [36], and 62\% [43] for good guesses of $\mathrm{AUC}_{\text {pred }}$ within $\pm 15 \%, \pm 20 \%$, or $\pm 25 \%$ of $\mathrm{AUC}_{\text {total }}$, respectively.

Based on the results of the predictive performance, the most promising MPA LSSs for renal transplant recipients were: $\mathrm{MPA} \mathrm{AUC}_{\text {pred }}=2.8401+5.7435 \times \mathrm{C} 0$ $+0.2655 \times \mathrm{C} 0.5+1.1546 \times \mathrm{C} 1+2.8971 \times \mathrm{C} 4$ if $\mathrm{CsA}$ was co-administered [41] and MPA $\mathrm{AUC}_{\text {pred }}=8.36+$ $7.49 \times \mathrm{C} 8+1.34 \times \mathrm{C} 2+1.66 \times \mathrm{C} 4+0.76 \times \mathrm{C} 1$ if Tac was co-administered [23]. The latter equation had the advantage of being validated in an external group of patients. The LSSs which was characterized by very good bias and precision was MPA AUC $\mathrm{Ared}=0.414+1.210 \times$ $\mathrm{C} 0.5+2.256 \times \mathrm{C} 1.5+4.134 \times \mathrm{C} 4$ [25], which had the advantages of being validated in a validation group and applied to patients receiving either CsA or Tac; however, the $r^{2}$ was $<0.950$. High $r^{2}$ was observed for the following equations: $\mathrm{AUC}_{\text {pred }}=8.32+0.904 \times \mathrm{C} 1.5+1.955$ $\times \mathrm{C} 4+10.206 \times \mathrm{C} 10$ [35], $\mathrm{AUC}_{\text {pred }}=15.3+7.06 \times$ $\mathrm{C} 4+6.77 \times \mathrm{C} 8-3.76 \times \mathrm{C} 12$, and $\mathrm{AUC}_{\text {pred }}=-0.247$ $+11.73 \times \mathrm{C} 6+2.92 \times \mathrm{C} 2$ [44]; however, the bias and precision were given in AUC units [35] or not given at all [44], so it is therefore difficult to compare these results with those expressed as percentages. For CsA co-treated patients, fMPA LSSs were characterized by high $r^{2}$ (> 0.950 ); however, precision was $>10 \%$ for all three equations and the validation was internal [40].

\subsection{The MLR-Based LSSs for Adult Patients Treated with MMF with Different Indication than Renal Transplantation}

Among other MMF indications in adults than rejection prophylaxis after renal transplantation, studies aiming at establishing LSS for liver transplant recipients $(n=5)$ [51, $54,57,58,60]$, heart transplant recipients $(n=5)[52,55$, $56,62,70]$, lung transplant recipients $(n=2)$ [50, 59], and hematopoietic stem cell transplant recipients $(n=2)$ [49, 61] were found. There were single studies including patients after islet transplantation [20], patients with autoimmune diseases (antineutrophil cytoplasmic antibody-associated systemic vasculitis and systemic lupus erythematosus) [53] and patients with anti-neutrophil cytoplasmic antibody-associated vasculitis [71] (Table 2). In one study, separate LSSs were established after oral and intravenous MMF administration for both total and fMPA [61]. One LSS consisted of $\mathrm{AUC}_{1-4}$ instead of particular time points [49].

The equations included up to four time points with three time-point LSSs being the most frequent (48\%). Of all time points, those collected within 0-2 $\mathrm{h}$ after MMF administration constituted $64 \%$ of the sum of all time points, whereas sampling between 3-5 $\mathrm{h}$ and 6-12 $\mathrm{h}$ after drug administration constituted $18 \%$ and $19 \%$, respectively.

Of 42 MLR equations, the most frequently used time points were $\mathrm{C} 2$ and $\mathrm{C} 1$. C2 was included in 28 (67\%) equations and constituted $22 \%$ of the sum of all time points from 42 equations, while $\mathrm{C} 1$ was included in 24 (57\%) equations and constituted $19 \%$ of all the time points from 42 equations. The number of 15 (36\%) equations including $\mathrm{C} 0$ and $\mathrm{C} 0$ constituted $12 \%$ of all time points. The most frequently included time point within 6-12 $\mathrm{h}$ after MMF administration was C6 (36\% of equations).

For other indications than renal transplantation, most MPA LSSs $(n=21)$ were established when Tac was co-administered. For these LSSs, the most frequent time points were $\mathrm{C} 1$ (24\% of all time points, $76 \%$ of the equations), $\mathrm{C} 2$, and $\mathrm{C} 4$ (19\% of all time points, $62 \%$ of the equations). Interestingly, for MMF and Tac coadministration, C0 was used in only two LSSs (10\%). For CsA co-administration (10 LSSs), the time points most often included were $\mathrm{C} 2$ (31\% of all time points, $100 \%$ of the equations), C6 (19\% of all time points, $60 \%$ of the equations), and $\mathrm{C} 1$ (16\% of all time points, $50 \%$ of the equations). C0 was used in four LSSs (40\%) and constituted $13 \%$ of all time points. Four LSSs established for patients among whom only $8 \%$ received CsA [53] were not included in this analysis. Additionally, there were six LSSs established for the group of patients treated with two agents, either MMF and CsA or MMF and Tac [59, 60]. Five of them included logarithmic concentrations and sampling up to $2 \mathrm{~h}$ after drug administration [59]. The 
sixth LSS which was established for patients receiving concomitantly with MMF CsA or Tac included only one time point, and its $\mathrm{r}^{2}$ was low (0.575) [60].

For LSSs established for patients treated with MMF less than 1 month, the most frequently included time points were $\mathrm{C} 2$ (27\% of all time points, $87 \%$ of the equations) and C6 (23\% of all time points, $73 \%$ of the equations). LSSs established for patients treated with MMF longer than 3 months most frequently consisted of $\mathrm{C} 2$ ( $24 \%$ of all time points, $69 \%$ of the equations), and C0 ( $22 \%$ of all time points, $62 \%$ of the equations).

The $r^{2}$ value of 0.98 was reached for four LSSs [20, 51, 61]. The bias was within $-1.1 \%$ to $20.4 \%$. No LSS was characterized by bias equal to 0 . The closest to zero bias was $0.15 \%$ [56] and -0.006 expressed as MPE [55]. The precision defined as mean or median absolute percentage prediction error or RMSE ranged from 8.24 to $16.35 \%$ and 5.81 to $26.8 \%$, respectively. The best results of $\mathrm{AUC}_{\text {pred }}$ within $\pm 15 \%$ of $\mathrm{AUC}_{\text {total }}$ amounted to $100 \%[56,59]$.

Based on the results of the predictive performance, the most promising MPA LSS were: $\mathrm{AUC}_{\text {pred }}=1.783+$ $1.248 \times \mathrm{C} 1+0.888 \times \mathrm{C} 2+8.027 \times \mathrm{C} 4[20]$ established for patients after islet transplantation and $\mathrm{AUC}_{\text {pred }}=$ $4.46+0.81 \times \mathrm{C} 1+1.78 \times \mathrm{C} 2+2.51 \times \mathrm{C} 4+4.94 \times$ C8 for liver transplant recipients [54]. Both equations were established for patients co-treated with Tac. For CsA co-treated patients after heart transplantation, the best LSS was $\mathrm{AUC}_{\text {pred }}=0.10+11.15 \times \mathrm{C} 0+0.42 \times \mathrm{C} 1+$ $2.80 \times \mathrm{C} 2$; however, precision was not shown [56]. The LSSs for Tac co-treated liver transplant recipients were characterized by very good bias and precision $\left(\mathrm{AUC}_{\text {pred }}\right.$ $=5.92+1.10 \times \mathrm{C} 1+1.01 \times \mathrm{C} 2+1.77 \times \mathrm{C} 4+4.80$ $\times \mathrm{C} 6$ [54] and $\mathrm{AUC}_{\text {pred }}=5.503+0.919 \times \mathrm{C} 1+1.871$ $\times \mathrm{C} 2+3.176 \times \mathrm{C} 6+3.664 \times \mathrm{C} 8$ [58]); however, $r^{2}$ was $<0.950$ in both cases. High $r^{2}$ was observed for externally validated LSS for CsA co-treated patients after hematopoietic stem cell transplantation $\left(\mathrm{AUC}_{\text {pred }}=-0.49\right.$ $+1.58 \times \mathrm{C} 2+0.41 \times \mathrm{C} 4+13.88 \times \mathrm{C} 6[61])$; however, the bias and precision were given in AUC units. The best LSS for fMPA, characterized by high $r^{2}$ and good bias and precision, was $\mathrm{AUC}_{\text {pred }}=34.2+1.12 \times \mathrm{C} 1+1.2$ $9 \times \mathrm{C} 2+2.28 \times \mathrm{C} 4+3.95 \times \mathrm{C} 6$, and was established for liver transplant recipients [51]. All five LSSs with log-transformed concentrations, established for lung transplant recipients, were characterized by good bias and precision; however, $r^{2}$ was $<0.90$ for all of them [59]. Another fMPA LSS, which was characterized by high $r^{2}$ $\left(\mathrm{AUC}_{\text {pred }}=7.99+1.40 \times \mathrm{C} 2+2.47 \times \mathrm{C} 4+9.54 \times\right.$ C6), was established for intravenous MMF administration and validated externally; however, the results of bias and precision were expressed in $\mathrm{ng} \cdot \mathrm{h} / \mathrm{mL}$ [61].

\subsection{The MLR-Based LSS for Pediatric Patients Treated with MMF}

A total of 25 LSSs established for pediatric patients were included. These LSSs were found in 11 studies [16-19, 63-69]. Most of these concerned children after renal transplantation $[16,17,65,66,68,69]$. There were three studies concerning nephrotic syndrome [19, 63, 64], one concerning systemic lupus erythematosus [18], and one which included both children after renal transplantation and with autoimmune diseases [67].

The equations included up to five time points. Three timepoint LSSs were the most frequent (64\%). Of all the time points, those collected within 0-2 $\mathrm{h}$ after MMF administration constituted $78 \%$ of all the time points, whereas sampling between $3-5 \mathrm{~h}$ and $6-12 \mathrm{~h}$ after drug administration constituted $11 \%$ and $10 \%$, respectively.

Of 25 MLR equations, the most frequently used time points were $\mathrm{C} 0$ and $\mathrm{C} 2$. Each of these concentrations was included in $19(76 \%)$ equations and constituted $24 \%$ of the sum of all time points from 25 equations. The most frequently included time point within $6-12 \mathrm{~h}$ after MMF administration was C6 (24\% of equations). Among 14 LSSs established for children after renal transplantation, the most frequently included time points were the same as for all the pediatric studies. C0 and C2 were included in 12 LSSs (86\%) and each constituted $29 \%$ of the sum of all time points from 14 equations.

Pediatric patients for whom MPA LSSs were established received concomitantly CsA (seven LSSs), Tac (two LSSs) or either CsA or Tac, but were analyzed together (eight LSSs). For eight LSSs, solely MMF was administered. The most frequently included time points only for LSSs established for children co-administered with CsA were analyzed. For these LSSs, the most frequent time points were C2 (32\% of all time points, $88 \%$ of the equations), $\mathrm{C} 0$ ( $26 \%$ of all time points, $71 \%$ of the equations), and $\mathrm{C} 0.5$ ( $16 \%$ of all time points, $43 \%$ of the equations).

The best $r^{2}$ was for three time points LSSs $(\mathrm{C} 1, \mathrm{C} 4, \mathrm{C} 8)$ and was established for children with nephrotic syndrome. The best LSSs for renal transplant recipients $\left(r^{2}=0.91\right)$ also included three time points $(\mathrm{C} 1, \mathrm{C} 2, \mathrm{C} 8)$. None of the equations reached $\mathrm{r}^{2}$ above 0.98 . Only four studies included the bias ( $-2.69 \%$ to $6.48 \%$ with $-0.39 \%$ being the closest to zero) and precision (2.87-12.92\%). In one study [19], the results of a good guess were shown (the percentage of $\mathrm{AUC}_{\text {pred }}$ within $\pm 15 \%$ of $\mathrm{AUC}_{\text {total }}$ ).

The best LSSs were $\mathrm{AUC}_{\text {pred }}=6.27+0.93 \times \mathrm{C} 0+$ $5.36 \times \mathrm{C} 4+6.56 \times \mathrm{C} 8$ [63], and $\mathrm{AUC}_{\text {pred }}=1.62+$ $2.22 \times \mathrm{C} 0+1.27 \times \mathrm{C} 1+2.32 \times \mathrm{C} 3+1.32 \times \mathrm{C} 4+3.07$ $\times$ C6 [19], both for children with nephrotic syndrome treated solely with MMF. For pediatric renal transplant recipients co-treated with Tac, the best LSS was $\mathrm{AUC}_{\text {pred }}=8.217$ 
$+3.163 \times \mathrm{C} 0+0.994 \times \mathrm{C} 1+1.334 \times \mathrm{C} 2+4.183 \times \mathrm{C} 4$; however, no bias and precision was included in the study [16]. Bias $<5 \%$ was observed for the following equation, $\mathrm{AUC}_{\text {pred }}=9.87+0.90 \times \mathrm{C} 1+1.73 \times \mathrm{C} 2+6.86 \times \mathrm{C} 8$, developed for pediatric renal transplant recipients, co-treated with CsA; however, $r^{2}$ was equal 0.91 in this case [65].

\subsection{Additional Information Concerning MPA LSSs Studies}

The detailed information on the patients' age, drugs coadministered with MMF, method used for MPA determination, and the duration of MMF treatment or time elapsed from the transplantation are presented in Table 4.

To characterize the patients, we extracted six age groups based on the mean age described in each study. In four articles $[30,46,47,61]$, the mean age of the patients was not defined. In two articles, only the range of patients' age was given (19-53 years [33] and 5-17 years [69]), not the mean. These studies are not included in Table 4 . In the majority of studies [18-20, 22, 25, 32-44, 46-49, 51, 52, 55-59, 61, $62,65,68,69]$, the high-performance liquid chromatography (HPLC) method was used for MPA determination. In 15 studies, MPA concentrations were determined based on enzyme multiplied immunoassay technique (EMIT) [16, 17, $24,27-29,45,53,54,60,63,65-67,71]$ (in one study both methods were applied [65]).

MMF was administered as dispersible tablets [23, 24, 70], suspension [65], or generic formulation [25, 33] apart from the standard formulation used in the majority of studies. In one study [61], LSSs were separately established for intravenous and oral MMF administration.

In Musuamba et al.'s study [30], the LSS included C3.5, which was calculated based on $\mathrm{C} 3$ and $\mathrm{C} 4$, as $\mathrm{C} 3.5$ was not collected. Moreover, although this study included both MMF- and EC-MPS-treated patients, most of the data were simulated.

\subsection{Limitations of the MPA LSSs Studies}

In the majority of the studies included in this review, the limitations concerned patients' characteristics. The most frequent limitation was a relatively small sample size [20, $26,31,32,36,41,43,45,48,49,56,70,71]$. The duration of MMF treatment was a limitation and concerned the substantial difference in the duration of treatment and regimens among patients [49, 64], late post-transplant period (approximately 4 years) [50] or narrow time range to the first two post-transplant weeks [70]. Some of the studies included patients of only one race in the evaluation $[19,50]$ or with trace proteinuria during the day of blood collection [19], others did not fully supervise the contribution of concomitant drugs $[16,19,26,64,71]$. Several studies excluded patients with gastrointestinal disease or diarrheal illness [32] or those with rejection or notable adverse effects [20, 41]. Few limitations concerned the pharmacokinetics, such as MPA LSS overprediction of AUC by $30 \%$ [61], low frequency of the sample collection at time intervals $[19,50]$, and the exclusion from the dataset of profiles with either extraordinarily high MPA $\mathrm{C}_{0}$ or delayed absorption $\left(t_{\max }>2 \mathrm{~h}\right)$ [36]. In one study, the lack of control patients was emphasized [64]. Other limitations included the limited universality of the LSS method [26, 48, 52].

\section{Discussion}

Estimating LSS is the approach of TDM applied for many drugs, e.g., MPA, levofloxacin, etoposide, moxifloxacin, ganciclovir, Tac, and CsA [72-78] in many diseases. Due to numerous factors influencing MPA pharmacokinetics, it is extremely difficult to establish a universal MPA LSS which might be applied in all MMF-treated patients. In our opinion, the review of MPA LSSs may be useful, as summaries of MLR LSSs for MPA which included the years up to 2009 [14] and up to 2013 [7] were found, and, therefore, this study contains the actual literature review. Moreover, some studies in which the LSS developed for one population was used to predict MPA exposition in an other population $[15,79,80]$ were found in the literature. The authors [15] observed that the application of LSS established for lung transplant recipients to predict MPA AUC in patients after heart transplant yielded satisfactory prediction results (bias and precision within $\pm 15 \%$ ); however, they concluded that the LSSs seem to be center-specific. Moreover, in Gellermann et al.'s study [81], the authors applied the LSSs established for children after renal transplantation and adult heart transplant recipients to evaluate AUC in children with nephrotic syndrome. In Katsuno et al.'s study [9], the LSS established for renal transplant recipients was used to predict AUC in patients with lupus nephritis. Additionally, Tong et al. [80] applied the LSS established with the HPLC method to evaluate AUC for patients for whom EMIT was used for MPA determination, while Neuberger et al. [79] applied MPA LSS established after EC-MPS administration in MMF-treated patients.

This review has included LSSs for total MPA generated with MLR mostly after oral MMF administration; however, there was one study [61] which included MPA LSS developed after separate oral and intravenous administration. Three studies established LSSs for fMPA [40, 51, 61]. There were also a few LSSs which included particular formulations, such as suspension [65], dispersible tablets [23, 24, $70]$, or a generic form of the drug [25, 33].

Most of the studies established LSSs with the intercept included, except those established by Kaczmarek et al. [55]. 


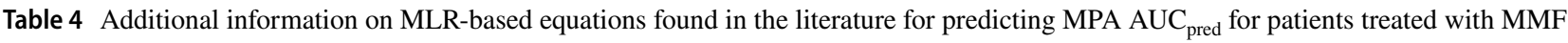

\begin{tabular}{|c|c|}
\hline Additional data & References \\
\hline \multicolumn{2}{|l|}{ Demographic data, age, years } \\
\hline $0-5$ & - \\
\hline $6-11$ & {$[17,19,63-65]$} \\
\hline$\geq 12$ & {$[16,18,66-68]$} \\
\hline $18-29$ & {$[35]$} \\
\hline $30-49$ & {$[23-29,31,32,36-40,42-45,48-52,56-59,70]$} \\
\hline$\geq 50$ & {$[20,34,41,53-55,60,62,71]$} \\
\hline \multicolumn{2}{|l|}{ Drugs co-administered } \\
\hline CsA & {$[34,41,45,49,53]^{\mathrm{a}},[61,64,66,67]$} \\
\hline CsA, corticosteroids & {$[17,25,35,36,39,40,42-45,47,48,52,56,59,60,62,64,65,69]$} \\
\hline Tac & {$[16,20,29,32,46,55,57,66,67]$} \\
\hline Tac, corticosteroids & {$[17,23-28,30,31,33,37,38,44,50,51,54,58-60,70]$} \\
\hline Steroids & {$[19,53,71]$} \\
\hline Sirolimus, daclizumab, corticosteroids & {$[34,36]$} \\
\hline None & {$[18,63,66,67]$} \\
\hline No information & {$[22]^{\mathrm{b}},[68]^{\mathrm{b}}$} \\
\hline \multicolumn{2}{|l|}{ Analytical method } \\
\hline HPLC & {$[18-20,22,25,32-44,46-49,51,52,55-59,61,62,65,68,69]$} \\
\hline UPLC-UV & {$[23]$} \\
\hline UPLC with photodiode array detection & {$[30]$} \\
\hline LC-MS/MS & {$[31,70]$} \\
\hline LC/ESI-MS/MS & {$[50]$} \\
\hline EMIT & {$[16,17,24,27-29,45,53,54,60,63,65-67,71]$} \\
\hline PETINIA technique & {$[26,64]$} \\
\hline \multicolumn{2}{|l|}{ Post-transplant time or the duration of MMF treatment } \\
\hline Pre-transplantation & [29] \\
\hline Within 7 days & {$[20,23,24,27,31,36,48,49,51,60,61,63]$} \\
\hline Within 7 days and 1 month & {$[16,30,35,37,39,40,43,46-48,54,57,58,60,65,66]^{\mathrm{c}},[67]^{\mathrm{c}},[68-70]^{\mathrm{d}},[71]^{\mathrm{c}}$} \\
\hline $1-3$ months & {$[16,20,29,36,41,42,44,46,52,53,62]$} \\
\hline 3 months & {$[18,46,47]$} \\
\hline$\geq 3$ months & {$[16,31,32]$} \\
\hline$<6$ months & {$[25]$} \\
\hline $3-6$ months & {$[33,36,44,65,68,69]$} \\
\hline $6-12$ months & {$[25,44,45,47,52,56,65]$} \\
\hline$<1$ year & {$[19,20,26,28,34,52]$} \\
\hline$>1$ year & {$[17,19,20,25,26,28,44,50,52,55,59,64,65]$} \\
\hline Stable post-transplant period, stable trough concentrations & {$[22]^{\mathrm{b}},[38]$} \\
\hline
\end{tabular}

$A U C_{\text {pred }}$ predicted area under the concentration-time (0-12 h) curve, $C s A$ cyclosporine, EMIT enzyme multiplied immunoassay technique, $H P L C$ high-performance liquid chromatography, LC/ESI-MS/MS liquid chromatography positive ion electrospray ionization tandem mass spectrometry, $L C-M S / M S$ liquid chromatography-tandem mass spectrometry, $M L R$ multiple linear regression, $M M F$ mycophenolate mofetil, $M P A$ mycophenolic acid, PETINIA homogeneous particle-enhanced turbidimetric inhibition immunoassay technique, Tac tacrolimus, UPLC-UV ultra-performance liquid chromatography with ultraviolet detection

${ }^{\text {a Only }} 3$ patients $(8 \%)$ received CsA

${ }^{\mathrm{b}}$ All information provided are based on the article abstract

${ }^{\mathrm{c}}$ Median 21 days after transplantation

${ }^{\mathrm{d}}$ At least 7 days, the upper time limit was not defined

${ }^{\mathrm{e}}$ At least 2 weeks, the upper time limit was not defined 
According to these authors [55], the equation without an intercept distributes relative prediction errors fairly evenly throughout the measuring range, whereas non-homogeneous models tend to yield larger relative prediction errors for lower values. However, the approach of not including the intercept was not found in other studies.

Among all MPA LSSs included in this review, the most often used time points were $2 \mathrm{~h}$ after MMF administration, that is near MPA $t_{\max }[1]$, and $6 \mathrm{~h}$ after MMF administration. Surprisingly, in adult renal transplant recipients, the most often used time point was $\mathrm{C} 4$, which is between $t_{\max }$ and $t_{\max 2}$ [82]. $\mathrm{C} 0$ was the most frequently included only in LSSs for pediatric patients. As MPA undergoes enterohepatic recirculation [2], it seems reasonable that, to describe MPA exposition accurately, the LSS should contain sampling over $6 \mathrm{~h}$ after MMF administration. Time points within 6-12 $\mathrm{h}$ after drug administration constituted less than $20 \%$ of all time points in each analyzed group. For adult transplant recipients, sampling within 3-5 h after MMF administration constituted a quarter of all time points.

Particular attention must be paid to the kind of calcineurin inhibitor co-administered. According to the literature, Tac does not influence MPA clearance [4]; however, in the case of CsA, MPA concentrations are lower if MMF and CsA are administered concomitantly [1]. CsA inhibits MPA enterohepatic recirculation [2] which causes the decrease in MPA exposition, and, therefore, in the case of CsA coadministration, the blood sampling does not require including time points around the second MPA maximum concentration $\left(C_{\max 2}\right)$ [7]. Comparing LSSs between patients treated concomitantly with CsA or Tac, the time points beyond 6 $\mathrm{h}$ were more frequently included in LSS when Tac was coadministered. For adult renal transplant recipients, the most frequently used time points were $\mathrm{C} 2$ and $\mathrm{C} 4$, and $\mathrm{C} 4$ and $\mathrm{C} 2$ if treated with MMF and CsA or MMF and Tac, respectively. When the indication for MMF treatment was different for renal transplantation, the most frequently used time points were $\mathrm{C} 2, \mathrm{C} 1$, and $\mathrm{C} 6$ and $\mathrm{C} 1, \mathrm{C} 2$, and $\mathrm{C} 4$ if $\mathrm{CsA}$ and Tac were co-administered, respectively. For pediatric patients, only a subgroup treated with MMF and CsA was evaluated as Tac co-treatment referred to only two LSSs. For MMF and CsA administration, in MPA LSSs, the most frequently included time points were $\mathrm{C} 2, \mathrm{C} 0$, and $\mathrm{C} 0.5$.

Constantly improving renal function after transplantation affects MPA pharmacokinetics [1]; therefore, some differences in time points included in LSSs which were established for patients treated with MMF less than 1 month after renal transplantation and longer than 3 months after renal transplantation were expected. Surprisingly, the most frequently used time points were within $4 \mathrm{~h}$ after drug administration irrespective of the post-transplant period $(\mathrm{C} 2$ and $\mathrm{C} 4$ and $\mathrm{C} 1$ and $\mathrm{C} 3$, for less than 1 month and longer than 3 months post-transplant, respectively). In MPA LSSs developed for patients with other than renal transplantation indication for MMF treatment, different sets of time points were used more frequently. These time points were $\mathrm{C} 2$ and $\mathrm{C} 6$ versus $\mathrm{C} 2$ and $\mathrm{C} 0$ for patients treated with MMF less than 1 month and longer than 3 months, respectively. For pediatric patients, the comparison of the results in relation to duration of MMF treatment were impossible to be found, as in most studies MPA LSSs were developed for children in the early as well as in stable post-transplant period or treated with MMF less than 1 month and longer than 3 months.

Some LSSs were used in numerous studies or applied in clinical practice to estimate MPA AUC and improve MPA TDM. Van Hest et al. [43] checked the utility of MPA LSS established for patients without diabetes in patients with diabetes and showed LSS suitability in the latter group. The LSS developed by Weber et al. [65] was applied to calculate MPA $\mathrm{AUC}_{0-12}$ and to obtain the optimal MMF dose in children after allogeneic hematopoietic cell transplantation [83]. The authors [83] proved that pharmacological monitoring of MPA $\mathrm{AUC}_{0-12}$ allowed a reduction in the incidence of acute and chronic graft-versus-host disease in patients who were undergoing prophylactic treatment with Tac and MMF. The MPA $\mathrm{AUC}_{0-12}$ was calculated using the LSS developed by Yamaguchi et al. [29] to evaluate the effects of UDPglucuronosyltransferases polymorphisms on the pharmacokinetics of MMF in Chinese renal transplant recipients [84]. MPA AUC $0-12$ estimated based on the LSS from the Musuamba et al. study [30] was used to check the influence of omeprazole on MMF pharmacokinetics in kidney transplant recipients [85]. Poulin et al. [32] used LSS to perform population pharmacokinetic analysis of Tac and MMF concomitant administration in adult kidney recipients [86] as well as to determine associations between the absolute neutrophil count, MPA exposure, and the polymorphisms in metabolism or transporter genes responsible for MPA disposition [87]. The LSS of Miura et al. [37] was applied in renal transplant recipients to check the utility of plasma level monitoring of MPA and to correlate it with clinical outcomes [88]. The LSS developed for autoimmune disease [53] was used to investigate MPA exposure in patients with systemic sclerosis treated with MMF [89].

We found a few LSSs with satisfactory bias and precision; however, the usefulness of some of them is limited by the inclusion of time points beyond $4 \mathrm{~h}$ after MMF administration. Some of the LSSs were characterized by good bias and precision, but the $r^{2}$ was $<0.90$. Nevertheless, several MLR-based LSSs might help in establishing MPA AUC total $_{1}$ for efficient TDM. With respect to the MMF indications, the following LSSs seems to be the most promising:

MPA AUC pred $=2.8401+5.7435 \times \mathrm{C} 0+0.2655 \times$ $\mathrm{C} 0.5+1.1546 \times \mathrm{C} 1+2.8971 \times \mathrm{C} 4$ for adult renal transplant recipients co-treated with CsA [41]; 
MPA $\mathrm{AUC}_{\text {pred }}=1.783+1.248 \times \mathrm{C} 1+0.888 \times \mathrm{C} 2+$ $8.027 \times \mathrm{C} 4$ for adult patients after islet transplantation co-treated with Tac [20];

MPA $\mathrm{AUC}_{\text {pred }}=0.10+11.15 \times \mathrm{C} 0+0.42 \times \mathrm{C} 1+$ $2.80 \times \mathrm{C} 2$ for adult patients after heart transplantation co-treated with CsA [56];

fMPA $\mathrm{AUC}_{\text {pred }}=34.2+1.12 \times \mathrm{C} 1+1.29 \times \mathrm{C} 2+2.28$ $\times \mathrm{C} 4+3.95 \times \mathrm{C} 6$ for adult liver transplant recipients [51];

MPA $\mathrm{AUC}_{\text {pred }}=8.217+3.163 \times \mathrm{C} 0+0.994 \times \mathrm{C} 1+$ $1.334 \times \mathrm{C} 2+4.183 \times \mathrm{C} 4$ for pediatric renal transplant recipients co-treated with Tac [16].

These LSSs require further evaluation in independent groups of patients before introducing them into clinical practice. The above LSS for fMPA might be difficult to implement as it included one time point $6 \mathrm{~h}$ after MMF administration. For MMF indications other than those listed above, we did not find any LSS which would fulfill the criteria of $r^{2}>0.95$ and precision and bias $<10 \%$. The usefulness of other LSSs with satisfactory results of predictive performance is limited by the inclusion of time points more than $4 \mathrm{~h}$ after drug administration. MPA LSSs established in pediatric populations were less numerous and rarely included the bias and precision. Moreover, we did not find any fMPA LSS established in a pediatric population. Those found for adult renal transplant recipients were not characterized by sufficient bias and precision, although, for these patients, fMPA monitoring should be of particular interest as it reflects the pharmacologically active form of the drug.

The limitation of our study is the lack of EMBASE search. Another limitation is that several articles did not fully characterize patient groups or did not show the results of predictive performance.

\section{Conclusions}

We found five MLR-based MPA LSSs which might be considered as useful in clinical practice; however, they require further evaluation in independent groups of patients. The LSSs for pediatric patients were less numerous and not fully characterized. There were only a few fMPA LSSs, although fMPA is a pharmacologically active form of the drug. For adult patients, MPA LSSs most frequently included $\mathrm{C} 2$ and $\mathrm{C} 4$, while, for pediatric patients, $\mathrm{C} 0$ and $\mathrm{C} 2$ were the most often used. The fact that the time points of MPA concentrations most frequently included in LSSs were different for adult renal transplant recipients, adults after other than renal transplantation, and in children treated with MMF, emphasizes the need of individual therapeutic approaches for each group of MMF-treated patients. Whereas the methodology of developing MPA LSS is rather a simple method enabling
TDM, establishing the most accurate MPA LSSs require numerous factors to be considered, such as the drugs coadministered with MMF (particularly calcineurin inhibitors), the time elapsed from the transplantation or the duration of treatment with MMF, and the indication for MMF treatment. LSS is a useful tool in MPA therapeutic monitoring; however, if sampling beyond few hours after MMF administration is required, optimizing drug dosage by the LSS approach appears to be less convenient.

\section{Declarations}

Funding No funding was received.

Conflict of interest No conflict of interest or competing interest to be declared.

Availability of data and material All resources analyzed in the writing of this review are listed in this published article.

Code availability Not applicable.

Author contributions Conceptualization: JS. Conducting the review: JS, MR. Data analysis: JS, MR. Writing the manuscript: JS. Reviewing and approving the manuscript: JS, MR.

Ethics approval Not applicable.

Consent to participate Not applicable.

Consent for publication Not applicable.

Open Access This article is licensed under a Creative Commons Attribution-NonCommercial 4.0 International License, which permits any non-commercial use, sharing, adaptation, distribution and reproduction in any medium or format, as long as you give appropriate credit to the original author(s) and the source, provide a link to the Creative Commons licence, and indicate if changes were made. The images or other third party material in this article are included in the article's Creative Commons licence, unless indicated otherwise in a credit line to the material. If material is not included in the article's Creative Commons licence and your intended use is not permitted by statutory regulation or exceeds the permitted use, you will need to obtain permission directly from the copyright holder. To view a copy of this licence, visit http://creativecommons.org/licenses/by-nc/4.0/.

\section{References}

1. Staatz CE, Tett SE. Clinical pharmacokinetics and pharmacodynamics of mycophenolate in solid organ transplant recipients. Clin Pharmacokinet. 2007;46:13-58.

2. Staatz CE, Tett SE. Pharmacology and toxicology of mycophenolate in organ transplant recipients: an update. Arch Toxicol. 2014;88:1351-89.

3. Ostalska-Nowicka D, Malinska A, Silska M, Perek B, Zachwieja J, Nowicki M. Mycophenolate mofetil (MMF) treatment efficacy in children with primary and secondary glomerulonephritis. Arch Med Sci. 2011;7:1042-8. 
4. Kiang TKL, Ensom MHH. Population pharmacokinetics of mycophenolic acid: an update. Clin Pharmacokinet. 2018;57:547-58.

5. Dias-Polak D, Bergman R, Avitan-Hersh E. Mycophenolate mofetil therapy in adult patients with recalcitrant atopic dermatitis. J Dermatol Treat. 2019;30:49-51.

6. Chen B, Gu Z, Chen H, Zhang W, Fen X, Cai W, et al. Establishment of high-performance liquid chromatography and enzyme multiplied immunoassay technology methods for determination of free mycophenolic acid and its application in Chinese liver transplant recipients. Ther Drug Monit. 2010;32:653-60.

7. Abd Rahman AN, Tett SE, Staatz CE. How accurate and precise are limited sampling strategies in estimating exposure to mycophenolic acid in people with autoimmune disease? Clin Pharmacokinet. 2014;53:227-45.

8. Filler G, Alvarez-Elías AC, McIntyre C, Medeiros M. The compelling case for therapeutic drug monitoring of mycophenolate mofetil therapy. Pediatr Nephrol. 2017;32:21-9.

9. Katsuno T, Ozaki T, Ozeki T, Hachiya A, Kim H, Kato N, et al. Investigation on the benefits of mycophenolate mofetil and therapeutic drug monitoring in the treatment of Japanese patients with lupus nephritis. Clin Exp Nephrol. 2018;22:1341-50.

10. Hackl Á, Cseprekál O, Gessner M, Liebau MC, Habbig S, Ehren $\mathrm{R}$, et al. Mycophenolate mofetil therapy in children with idiopathic nephrotic syndrome: does therapeutic drug monitoring make a difference? Ther Drug Monit. 2016;38:274-9.

11. Tellier S, Dallocchio A, Guigonis V, Saint-Marcoux F, Llanas B, Ichay L, et al. Mycophenolic acid pharmacokinetics and relapse in children with steroid-dependent idiopathic nephrotic syndrome. Clin J Am Soc Nephrol. 2016;11:1777-82.

12. Sobiak J, Resztak M, Ostalska-Nowicka D, Zachwieja J, Gąsiorowska K, Piechanowska W, et al. Monitoring of mycophenolate mofetil metabolites in children with nephrotic syndrome and the proposed novel target values of pharmacokinetic parameters. Eur J Pharm Sci. 2015;77:189-96.

13. Saint-Marcoux F, Guigonis V, Decramer S, Gandia P, Ranchin B, Parant F, et al. Development of a Bayesian estimator for the therapeutic drug monitoring of mycophenolate mofetil in children with idiopathic nephrotic syndrome. Pharmacol Res. 2011;63:423-31.

14. Bruchet NK, Ensom MH. Limited sampling strategies for mycophenolic acid in solid organ transplantation: a systematic review. Expert Opin Drug Metab Toxicol. 2009;5:1079-97.

15. Ting LSL, Partovi N, Levy RD, Ignaszewski AP, Ensom MHH. Performance of limited sampling strategies for predicting mycophenolic acid area under the curve in thoracic transplant recipients. J Heart Lung Transplant. 2008;27:325-8.

16. Filler G. Abbreviated mycophenolic acid AUC from $\mathrm{CO}, \mathrm{C} 1$, $\mathrm{C} 2$, and $\mathrm{C} 4$ is preferable in children after renal transplantation on mycophenolate mofetil and tacrolimus therapy. Transpl Int. 2004;17:120-5.

17. David-Neto E, Araujo LMP, Sumita NM, Mendes ME, Castro MCR, Alves CF, et al. Mycophenolic acid pharmacokinetics in stable pediatric renal transplantation. Pediatr Nephrol. 2003;18:266-72.

18. Prabha R, Mathew B, Jeyaseelan V, Kumar T, Agarwal I, Fleming D. Development and validation of limited sampling strategy equation for mycophenolate mofetil in children with systemic lupus erythematosus. Indian J Nephrol. 2016;26:408-12.

19. Sobiak J, Resztak M, Pawiński T, Żero P, Ostalska-Nowicka D, Zachwieja J, et al. Limited sampling strategy to predict mycophenolic acid area under the curve in pediatric patients with nephrotic syndrome: a retrospective cohort study. Eur J Clin Pharmacol. 2019;75:1249-59.

20. Al-Khatib M, Shapiro RJ, Partovi N, Ting LS, Levine M, Ensom $\mathrm{MH}$. Limited sampling strategies for predicting area under the concentration-time curve of mycophenolic acid in islet transplant recipients. Ann Pharmacother. 2010;44:19-27.

21. Jia Y, Peng B, Li L, Wang J, Wang X, Qi G, et al. Estimation of mycophenolic acid area under the curve with limited-sampling strategy in chinese renal transplant recipients receiving entericcoated mycophenolate sodium. Ther Drug Monit. 2017;39:29-36.

22. Karimani A, Abedi H, Nazemian F, Poortaji A, Pour AHM. Estimation of abbreviated mycophenolic acid area under the concentration-time curve during stable post-transplant period by limited sampling strategy. Curr Clin Pharmacol. 2020. https://doi.org/10. 2174/1574884715666200827104813.

23. Zhang J, Sun Z, Zhu Z, Yang J, Kang J, Feng G, et al. Pharmacokinetics of mycophenolate mofetil and development of limited sampling strategy in early kidney transplant recipients. Front Pharmacol. 2018;9:908.

24. Cai W, Cai Q, Xiong N, Qin Y, Lai L, Sun X, et al. Limited sampling strategy for estimating mycophenolic acid exposure on day 7 post-transplant for two mycophenolate mofetil formulations derived from 20 Chinese renal transplant recipients. Transplant Proc. 2018;50:1298-304.

25. Gaies E, Ben Sassi M, El Jebari H, Jebabli N, Charfi R, Chokri I, et al. Limited sampling strategy for the estimation of mycophenolic acid area under the curve in Tunisian renal transplant patients. Nephrol Ther. 2017;13:460-2.

26. Enokiya T, Nishikawa K, Muraki Y, Iwamoto T, Kanda H, Sugimura $Y$, et al. Usefulness of limited sampling strategy for mycophenolic acid area under the curve considering postoperative days in living-donor renal transplant recipients with concomitant prolonged-release tacrolimus. J Pharm Health Care Sci. 2017;3:17

27. Cai W, Ye C, Sun X, Qin K, Qin Y, Zhao D, et al. Limited sampling strategy for predicting area under the concentrationtime curve for mycophenolic acid in Chinese adults receiving mycophenolate mofetil and tacrolimus early after renal transplantation. Ther Drug Monit. 2015;37:304-10.

28. Chaabane A, Aouam K, Fredj NB, Hammouda M, Chadly Z, May ME, et al. Limited sampling strategy of mycophenolic acid in adult kidney transplant recipients: influence of the post-transplant period and the pharmacokinetic profile. J Clin Pharmacol. 2013;53:925-33.

29. Yamaguchi K, Fukuoka N, Kimura S, Watanabe M, Tani K, Tanaka H, et al. Limited sampling strategy for the estimation of mycophenolic acid area under the concentration-time curve treated in japanese living-related renal transplant recipients with concomitant extended-release tacrolimus. Biol Pharm Bull. 2013;36:1036-9.

30. Musuamba FT, Mourad M, Haufroid V, De Meyer M, Capron A, Delattre IK, et al. Statistical tools for dose individualization of mycophenolic acid and tacrolimus co-administered during the first month after renal transplantation. Br J Clin Pharmacol. 2013;75:1277-88.

31. Barraclough KA, Isbel NM, Johnson DW, Hawley CM, Lee KJ, Mcwhinney BC, et al. A limited sampling strategy for the simultaneous estimation of tacrolimus, mycophenolic acid and unbound prednisolone exposure in adult kidney transplant recipients. Nephrology. 2012;17:294-9.

32. Poulin E, Greanya ED, Partovi N, Shapiro RJ, Al-Khatib M, Ensom MHH. Development and validation of limited sampling strategies for tacrolimus and mycophenolate in steroid-free renal transplant regimens. Ther Drug Monit. 2011;33:50-5.

33. Mathew BS, Fleming DH, Annapandian VM, Prasanna S, Prasanna CG, Chandy SJ, et al. A reliable limited sampling strategy for the estimation of mycophenolic acid area under the concentration time curve in adult renal transplant patients in the stable posttransplant period. Ther Drug Monit. 2010;32:136-40. 
34. Musuamba FT, Rousseau A, Bosmans J-L, Senessael J-J, Cumps $\mathrm{J}$, Marquet $\mathrm{P}$, et al. Limited sampling models and bayesian estimation for mycophenolic acid area under the curve prediction in stable renal transplant patients co-medicated with ciclosporin or sirolimus. Clin Pharmacokinet. 2009;48:745-58.

35. Mohammadpour A-H, Nazemian F, Abtahi B, Naghibi M, Gholami K, Rezaee S, et al. Estimation of abbreviated mycophenolic acid area under the concentration-time curve during early posttransplant period by limited sampling strategy. Transplant Proc. 2008;40:3668-72.

36. Figurski MJ, Nawrocki A, Pescovitz MD, Bouw R, Shaw LM. Development of a predictive limited sampling strategy for estimation of mycophenolic acid area under the concentration time curve in patients receiving concomitant sirolimus or cyclosporine. Ther Drug Monit. 2008;30:445-55.

37. Miura M, Satoh S, Niioka T, Kagaya H, Saito M, Hayakari M, et al. Limited sampling strategy for simultaneous estimation of the area under the concentration-time curve of tacrolimus and mycophenolic acid in adult renal transplant recipients. Ther Drug Monit. 2008;30:52-9.

38. Teshima D, Maiguma T, Kaji H, Otsubo K, Kitagawa N, Okabe $\mathrm{Y}$, et al. Estimation of the area under the curve for mycophenolic acid in adult renal transplant patients with concomitant tacrolimus using a limited sampling strategy. J Clin Pharm Ther. 2008;33:159-63.

39. Zhou P-J, Xu D, Yu Z-C, Wang X-H, Shao K, Zhao J-P. Pharmacokinetics of mycophenolic acid and estimation of exposure using multiple linear regression equations in Chinese renal allograft recipients. Clin Pharmacokinet. 2007;46:389-401.

40. Jiao Z, Zhong J, Zhang M, Shi X, Yu Y, Lu W. Total and free mycophenolic acid and its 7-O-glucuronide metabolite in Chinese adult renal transplant patients: pharmacokinetics and application of limited sampling strategies. Eur J Clin Pharmacol. 2007;63:27-37.

41. Wang CX, Meng FH, Chen LZ, Ren B, Li SX, Fei JG, et al. Population pharmacokinetics of mycophenolic acid in senile Chinese kidney transplant recipients. Transplant Proc. 2007;39:1392-5.

42. Zicheng Y, Peijun Z, Da X, Xianghui W, Hongzhuan C. Investigation on pharmacokinetics of mycophenolic acid in Chinese adult renal transplant patients. Br J Clin Pharmacol. 2006;62:446-52.

43. van Hest RM, Mathôt RAA, Vulto AG, Le Meur Y, van Gelder T. Mycophenolic acid in diabetic renal transplant recipients: pharmacokinetics and application of a limited sampling strategy. Ther Drug Monit. 2004;26:620-5.

44. Kuriata-Kordek M, Boratynska M, Falkiewicz K, Porazko T, Urbaniak J, Wozniak M, et al. The influence of calcineurin inhibitors on mycophenolic acid pharmacokinetics. Transplant Proc. 2003;35:2369-71.

45. Guellec CL, Büchler M, Giraudeau B, Meur YL, Gakoué J-E, Lebranchu Y, et al. Simultaneous estimation of cyclosporin and mycophenolic acid areas under the curve in stable renal transplant patients using a limited sampling strategy. Eur J Clin Pharmacol. 2002;57:805-11

46. Pawinski T, Hale M, Korecka M, Fitzsimmons WE, Shaw LM. Limited sampling strategy for the estimation of mycophenolic acid area under the curve in adult renal transplant patients treated with concomitant tacrolimus. Clin Chem. 2002;48:1497-504.

47. Yeung S, Tong KL, Tsang WK, Tang HL, Fung KS, Chan HWH, et al. Determination of mycophenolate area under the curve by limited sampling strategy. Transplant Proc. 2001;33:1052-3.

48. Johnson AG, Rigby RJ, Taylor PJ, Jones CE, Allen J, Franzen $\mathrm{K}$, et al. The kinetics of mycophenolic acid and its glucuronide metabolite in adult kidney transplant recipients. Clin Pharmacol Ther. 1999;66:492-500.

49. Gota V, Purohit V, Gurjar M, Nayak L, Punatar S, Gokarn A, et al. A limited sampling strategy for therapeutic drug monitoring of mycophenolate mofetil for prophylaxis of acute graft-versus-host disease in allogeneic stem cell transplantation. Cell Transplant. 2020;29:0963689720912925.

50. Tanaka M, Kikuchi M, Takasaki S, Hirasawa T, Sigeta K, Noda A, et al. Limited sampling strategy for the estimation of mycophenolic acid and its acyl glucuronide metabolite area under the concentration-time curve in japanese lung transplant recipients. J Pharm Pharm Sci. 2019;22:407-17.

51. Gu Z, Chen B, Song Y, Shen B, Zhu Z, Zhang W, et al. Pharmacokinetics of free mycophenolic acid and limited sampling strategy for the estimation of area under the curve in liver transplant patients. Eur J Pharm Sci. 2012;47:636-41.

52. Pawinski T, Kunicki PK, Sobieszczanska-Malek M, Gralak B, Szlaska I. A limited sampling strategy for estimating mycophenolic acid area under the curve in adult heart transplant patients treated with concomitant cyclosporine. J Clin Pharm Ther. 2009;34:89-101.

53. de Winter B, Neumann I, van Hest R, Gelder T, Mathot R. Limited sampling strategies for therapeutic drug monitoring of mycophenolate mofetil therapy in patients with autoimmune disease. Ther Drug Monit. 2009;31:382-90.

54. Chen H, Gu Z, Chen B, Mao H, Zhang W, Fan Q. Models for the prediction of mycophenolic acid area under the curve using a limited-sampling strategy and an enzyme multiplied immunoassay technique in Chinese patients undergoing liver transplantation. Clin Ther. 2008;30:2387-401.

55. Kaczmarek I, Bigdeli AK, Vogeser M, Mueller T, Beiras-Fernandez A, Kaczmarek P, et al. Defining algorithms for efficient therapeutic drug monitoring of mycophenolate mofetil in heart transplant recipients. Ther Drug Monit. 2008;30:419-27.

56. Wada K, Takada M, Kotake T, Ochi H, Morishita H, Komamura $\mathrm{K}$, et al. Limited sampling strategy for mycophenolic acid in Japanese heart transplant recipients. Circ J. 2007;71:1022-8.

57. Zicheng Y, Weixia Z, Hao C, Hongzhuan C. Limited sampling strategy for the estimation of mycophenolic acid area under the plasma concentration-time curve in adult patients undergoing liver transplant. Ther Drug Monit. 2007;29:207-14.

58. Chen H, Peng C, Yu Z, Shen B, Deng X, Qiu W, et al. Pharmacokinetics of mycophenolic acid and determination of area under the curve by abbreviated sampling strategy in Chinese liver transplant recipients. Clin Pharmacokinet. 2007;46:175-85.

59. Ting LSL, Partovi N, Levy RD, Riggs KW, Ensom MHH. Limited sampling strategy for predicting area under the concentration-time curve of mycophenolic acid in adult lung transplant recipients. Pharmacotherapy. 2006;26:1232-40.

60. Fatela-Cantillo D, Hinojosa-Pérez R, Peralvo-Rodríguez MI, Serrano-Díaz Canedo J, Gómez-Bravo MA. Pharmacokinetic evaluation of mycophenolic acid profiles during the period immediately following an orthotopic liver transplant. Transplant Proc. 2006;38:2482-5.

61. Ng J, Rogosheske J, Barker J, Weisdorf D, Jacobson PA. A limited sampling model for estimation of total and unbound mycophenolic acid (MPA) area under the curve (AUC) in hematopoietic cell transplantation (HCT). Ther Drug Monit. 2006;28:394-401.

62. Baraldo M, Isola M, Feruglio MT, Francesconi A, Franceschi L, Tursi V, et al. Therapeutic mycophenolic acid monitoring by means of limited sampling strategy in orthotopic heart transplant patients. Transplant Proc. 2005;37:2240-3.

63. Benz M, Ehren R, Kleinert D, Müller C, Gellermann J, Fehrenbach $\mathrm{H}$, et al. Generation and validation of a limited sampling strategy to monitor mycophenolic acid exposure in children with nephrotic syndrome. Ther Drug Monit. 2019;41:696-702.

64. Hibino S, Nagai T, Yamakawa S, Ito H, Tanaka K, Uemura O. Pharmacokinetics of mycophenolic acid in children with clinically stable idiopathic nephrotic syndrome receiving cyclosporine. Clin Exp Nephrol. 2017;21:152-8. 
65. Weber LT, Hoecker B, Armstrong VW, Oellerich M, Tönshoff B. Validation of an abbreviated pharmacokinetic profile for the estimation of mycophenolic acid exposure in pediatric renal transplant recipients. Ther Drug Monit. 2006;28:623-31.

66. Filler G, Feber J, Lepage N, Weiler G, Mai I. Universal approach to pharmacokinetic monitoring of immunosuppressive agents in children. Pediatr Transplant. 2002;6:411-8.

67. Filler G, Mai I. Limited sampling strategy for mycophenolic acid area under the curve. Ther Drug Monit. 2000;22:169-73.

68. Weber LT, Schütz E, Lamersdorf T, Shipkova M, Niedmann PD, Oellerich M, et al. Therapeutic drug monitoring of total and free mycophenolic acid (MPA) and limited sampling strategy for determination of MPA-AUC in paediatric renal transplant recipients. The German Study Group on Mycophenolate Mofetil (MMF) Therapy. Nephrol Dial Transplant. 1999;14:34-5.

69. Schütz E, Armstrong VW, Shipkova M, Weber L, Niedmann PD, Lammersdorf $\mathrm{T}$, et al. Limited sampling strategy for the determination of mycophenolic acid area under the curve in pediatric kidney recipients. 11 Additional contributing investigators from the German Study Group (in alphabetical order of the centers): R. Böswald, H. Ruder (Erlangen), M. Schröder, J. Dippel (Frankfurt), A. Staskewitz, G. Kirste (Freiburg), M. Holder, H. Leichter (Stuttgart). Transplant Proc. 1998;30:1182-4.

70. Xiang H, Zhou H, Zhang J, Sun Y, Wang Y, Han Y, et al. Limited sampling strategy for estimation of mycophenolic acid exposure in adult Chinese heart transplant recipients. Front Pharmacol. $2021 ; 12: 652333$

71. Chaigne B, Gatault P, Darrouzain F, Barbet C, Degenne D, François $\mathrm{M}$, et al. Mycophenolate mofetil in patients with antineutrophil cytoplasmic antibody-associated vasculitis: a prospective pharmacokinetics and clinical study. Clin Exp Immunol. 2014;176:172-9.

72. Pawinski T, Luszczynska P, Durlik M, Majchrzak J, Baczkowska $\mathrm{T}$, Chrzanowska M, et al. Development and validation of limited sampling strategies for the estimation of mycophenolic acid area under the curve in adult kidney and liver transplant recipients receiving concomitant enteric-coated mycophenolate sodium and tacrolimus. Ther Drug Monit. 2013;35:760-9.

73. Czyrski A, Kondys K, Szałek E, Karbownik A, Grześkowiak E. The pharmacokinetic interaction between levofloxacin and sunitinib. Pharmacol Rep. 2015;67:542-4.

74. Danielak D, Sobiak J, Wachowiak J, Glówka F, Chrzanowska M. Development of a limited sampling strategy for the estimation of exposure to high-dose etoposide after intravenous infusion in pediatric patients. Ther Drug Monit. 2017;39:138-44.

75. van den Elsen SHJ, Sturkenboom MGG, Akkerman OW, Manika K, Kioumis IP, van der Werf TS, et al. Limited sampling strategies using linear regression and the bayesian approach for therapeutic drug monitoring of moxifloxacin in tuberculosis patients. Antimicrob Agents Chemother. 2019;63:e00384-e419.

76. Rui W-B, An H-M, Shao K, Zhai X-H, Lu J-Q, Hu S-S, et al. Limited sampling strategy for the estimation of the area under the concentration-time curve for ganciclovir in Chinese adult renal allograft recipients. Eur J Clin Pharmacol. 2019;75:677-86.

77. Vadcharavivad S, Susomboon T, Kulabusaya B, Avihingsanon Y, Praditpornsilpa K, Townamchai N. Validation of a 2-point limited sampling strategy to predict the tacrolimus area-under-the12-hour-curve in kidney transplant recipients. Ther Drug Monit. 2016;38:614-20.

78. Sarem $S$, Nekka F, Barrière $O$, Bittencourt H, Duval M, Teira P, et al. Limited sampling strategies for estimating intravenous and oral cyclosporine area under the curve in pediatric hematopoietic stem cell transplantation. Ther Drug Monit. 2015;37:198-205.

79. Neuberger M, Sommerer C, Böhnisch S, Metzendorf N, Mehrabi A, Stremmel W, et al. Effect of mycophenolic acid on inosine monophosphate dehydrogenase (IMPDH) activity in liver transplant patients. Clin Res Hepatol Gastroenterol. 2020;44:543-50.

80. Tong K, Mao J, Fu H, Shen H, Liu A, Shu Q, et al. The value of monitoring the serum concentration of mycophenolate mofetil in children with steroid-dependent/frequent relapsing nephrotic syndrome. Nephron. 2016;132:327-34.

81. Gellermann J, Weber L, Pape L, Tönshoff B, Hoyer P, Querfeld U. Mycophenolate mofetil versus cyclosporin A in children with frequently relapsing nephrotic syndrome. J Am Soc Nephrol. 2013;24:1689-97.

82. Ehren R, Schijvens AM, Hackl A, Schreuder MF, Weber LT. Therapeutic drug monitoring of mycophenolate mofetil in pediatric patients: novel techniques and current opinion. Expert Opin Drug Metab Toxicol. 2020;17:201-13.

83. Carlone G, Simeone R, Baraldo M, Maestro A, Zanon D, Barbi $\mathrm{E}$, et al. Area-under-the-curve-based mycophenolate mofetil dosage may contribute to decrease the incidence of graft-versus-host disease after allogeneic hematopoietic cell transplantation in pediatric patients. J Clin Med. 2021;10:406.

84. Xie X, Li J, Wang H, Li H, Liu J, Fu Q, et al. Associations of UDP-glucuronosyltransferases polymorphisms with mycophenolate mofetil pharmacokinetics in Chinese renal transplant patients. Acta Pharmacol Sin. 2015;36:644-50.

85. AbdElhalim MS, Kenawy AS, Demellawy HHE, Azouz AA, Alghanem SS, Al-Otaibi T, et al. The impact of omeprazole on mycophenolate pharmacokinetics in kidney transplant recipients. Kidney Res Clin Pract. 2020;39:479-86.

86. Rong Y, Mayo P, Ensom MHH, Kiang TKL. Population pharmacokinetic analysis of immediate-release oral tacrolimus co-administered with mycophenolate mofetil in corticosteroid-free adult kidney transplant recipients. Eur J Drug Metab Pharmacokinet. 2019;44:409-22.

87. Kiang TKL, Partovi N, Shapiro RJ, Berman JM, Collier AC, Ensom MHH. Regression and genomic analyses on the association between dose-normalized mycophenolic acid exposure and absolute neutrophil count in steroid-free, de novo kidney transplant recipients. Clin Drug Investig. 2018;38:1011-22.

88. Sarangi SC, Reeta KH, Agarwal SK, Kaleekal T, Guleria S, Gupta YK. A pilot study on area under curve of mycophenolic acid as a guide for its optimal use in renal transplant recipients. Indian $\mathbf{J}$ Med Res. 2012;135:84-91.

89. Andréasson K, Neringer K, Wuttge DM, Henrohn D, Marsal J, Hesselstrand R. Mycophenolate mofetil for systemic sclerosis: drug exposure exhibits considerable inter-individual variation-a prospective, observational study. Arthritis Res Ther. 2020;22:230. 